\title{
CONDITIONS OF PROPER INTERACTION OF LOW-PRESSURE INJECTION PILES (LIP) WITH STRUCTURE AND SOIL, CARRYING CAPACITY OF PILE ANCHORAGE IN FOUNDATION
}

\author{
HENRYK PACHLA \\ ul. Lecha 16, 30-565 Kraków, Poland, e-mail: h.pachla@kroz.pl
}

\begin{abstract}
The formation of a pile in the existing foundation and soil creates a new foundation construction which has a structure of foundation-pile-soil. This construction must be able to transfer loads from the foundation to the pile and from the pile to the soil. The pile structure has to transfer an imposed load. From the point of view of continuum mechanics determination of the capacity of such a system is preceded by the analysis of contact problem of three contact surfaces. Each of these surfaces is determined by different pairs of materials. The pair which creates a pile anchorage is a material from which the foundation is built (structure of stone and grout, brick and grout, concrete or reinforced concrete and grout.

The pile structure is formed by grout and steel rebar. The pile formed in soil is created by a pair of grout and soil. What is important is that on contact surfaces the materials adhering to one another are subjected to different deformation types that are controlled by mechanical properties and geometry of these surfaces.

In the paper, additional conditions that should be fulfilled for the foundation-pile-soil system to make load transfer from foundation to soil possible and safe are presented. The results of research done by the author on foundation-pile contact surface are discussed. The tests were targeted at verifying the bearing capacity of anchorage and deformation of piles made of grout and other materials from which foundations are built. The specimens were tested in tension and compression. The experiments were conducted on the amount specimens which is regarded as small sample to enable the statistical analysis of the results.
\end{abstract}

Key words: low-pressure injection piles, pile anchorage in foundation, contact surface, foundation design

\section{INTRODUCTION}

Low-pressure injection piles are classified into the group of piles in which the building material is grout pumped under pressure to the borehole. Injection piles are drilled piles of diameters not exceeding $25 \mathrm{~cm}$. 15 to $20 \mathrm{~cm}$ diameter piles are formed most often. Cement grout is a widely applied type of grout, which is pumped under pressure of several atmospheres to the bottom of the borehole at the same direction of drilling (Fig. 1a). Injection piles are also formed under pressure perpendicular to the drilling direction (Fig. 1b). This group of piles includes medium-pressure piles formed under pressure of several dozen atmospheres (e.g., Titan piles) and high-pressure piles formed under pressure of several hundred atmospheres. Depending on pressure magnitude the diameters of these piles (columns) can be very large. Due to torsional grouting (return motion upward) the pile is partly or fully a mixture of grout and soil. The term "micropile", which is commonly used in literature for lowpressure and medium-pressure piles, does not reflect the specificity of these technologies, and goes back to the times when pressure technology was basically used to form only low-pressure piles with very small diameters of 7 to $12 \mathrm{~cm}$.

During pile formation under newly built superstructures or geotechnical structures pile load tests are a standard procedure. Test results create a comprehensive reference literature on the behaviour of concrete piles of large diameter used in such projects, or large diameter injection columns, of considerable loadbearing capacity used in other technologies [1]. However, the scope of application of these tests is limited by the level of loads recommended in standards and feasible in field conditions.

The pile load test is very rarely performed because of direct pile anchorage in the existing foundations through holes drilled in the foundations and changeable soil conditions in the immediate vicinity of piles, which makes such tests of limited use. 


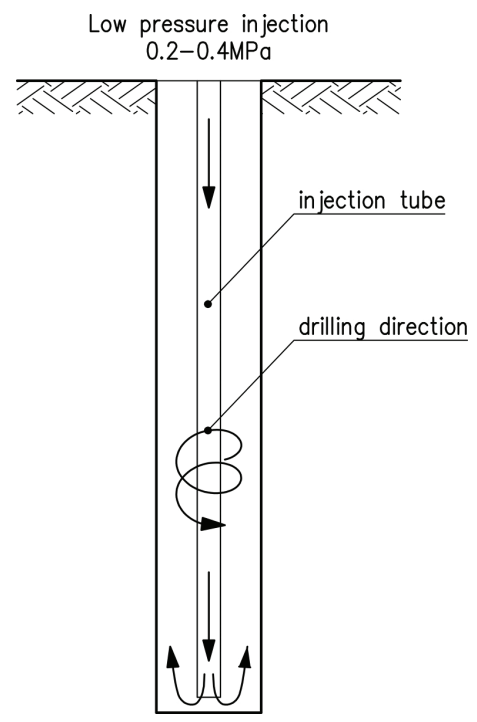

Fig. 1a. Diagram of low pressure injection

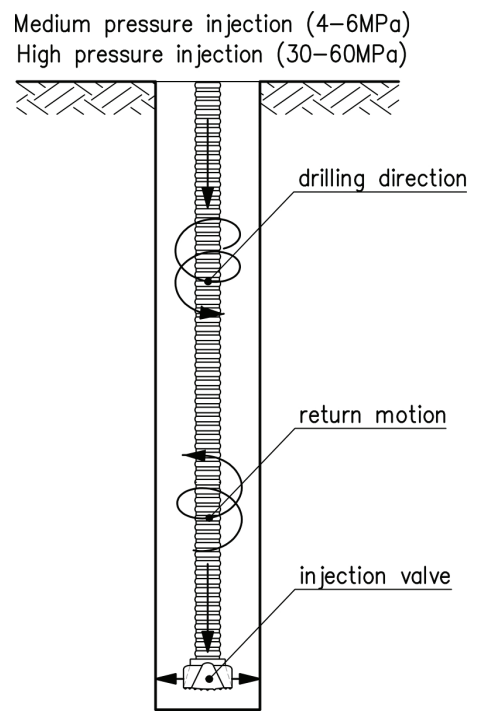

Fig. 1b. Diagram of medium and high pressure injection
In consequence, the papers discussing experiments and analysis of mechanical processes in various loading conditions for this group of piles present only laboratory tests and theoretical analyses [8]-[18].

Long-standing practice of forming low-pressure injection piles and verification of the existing ones in historic development areas as well as the arguments presented above motivated us to perform a series of tests, the first part of which is presented in this article.

\section{CONDITIONS OF PROPER PILE INTERACTION WITH STRUCTURE AND SOIL}

The aim of piling is to transfer loads from a building to deeper, "firmer" soil layers through foundations.

The ability to transfer loads to soil by foundationpile-soil structure is determined by the interaction between these three elements (Fig. 2). For low-injection piles each of these elements is made of different material. The amount of load which can be applied is determined by the interaction of these elements. First, it is the interaction between foundation and pile, often called pile anchorage. In this case the bonding between the material of which the foundation is made and the grout which forms the pile.

It is also important that the amount of load applied to a pile does not destroy it and its internal cohesion determined by steel elements-grout bond is maintained.

The load transfer from the pile to soil is determined by the grout-soil bond.

One of the limit conditions recommended in European standards [2] which should be considered during the designing process is the fatigue limit state of pile foundation bearing capacity exhaustion, including the exhaustion of the capacity of the interaction between each element of the foundation-pile-soil structure. However, the proposed serviceability limit states concern only limitation of displacements and vibrations of pile foundation as a whole in contact with soil.

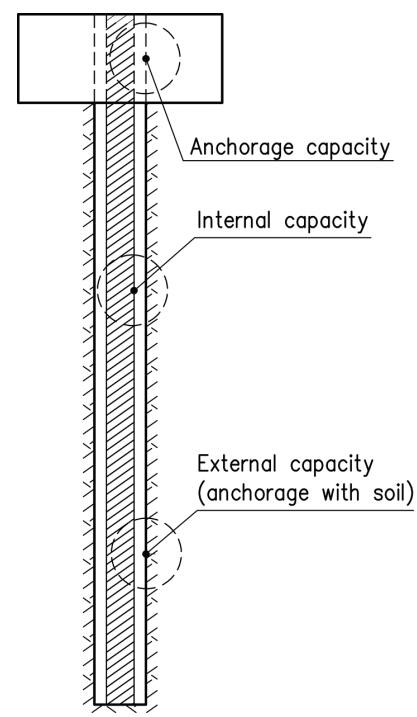

Fig. 2. Foundation-pile-soil connection surface

In newly built foundations pile anchorage is executed by connecting the reinforcement of pile and the reinforcement of foundation. Pile anchorage in existing foundations requires a different technology.

In different periods in the past foundations were made of various construction materials and most frequently were not reinforced. The basic historical materials used for foundations include stone, ceramic brick and various types of grout as binding material, 
while recently the foundation material is mainly concrete and reinforced concrete.

The pile transferring loads from the foundation to deeper soil layers is usually formed in a hole drilled through the foundation or foundation wall. Most frequently there is no additional anchorage of the pile into the foundation. The load is transferred from the foundation onto the pile through friction forces on the pile-foundation interface.

From the point of view of continuum mechanics, mechanical state variables are a solution of contact tasks in which the contact surface is determined by the pile periphery. In case of this connection losing its load bearing capacity, the pile is not loaded and becomes useless. If anchorage capacity is defined as a maximum load that can be carried by pile-foundation connection, the condition of safe operation of the foundation-pilesoil structure has to be fulfilled

$$
F \leq n_{c} N_{c}
$$

where $F$ - load to be transferred by anchorage, $N_{c}$ - anchorage bearing capacity, $n_{c}$ - factor of safety.

Low-pressure injection piles are most commonly made from reinforced cement grout. Piles are reinforced mainly with various types of steel elements. The reinforcement used most frequently includes cages made from ribbed steel bars, individual steel bars of larger diameters, perforated steel tubes and steel profiles. In each of the cases mentioned above what is most important apart from the strengths of steel and cement grout is the strength of the bond between the two materials. In the case of loss of this bond, the pile periphery that transfers through friction a significant part of the load disintegrates.

The variables defining the mechanical state of a pile structure composed of two materials are a solution of the contact problem of contact surface determined by the surface of reinforcement grouted in cement.

Defects on pile periphery prevent load transfer to soil, which in consequence makes the whole pile useless. Let us assume that the maximum load that can be carried by steel-cement grout connection defines the pile internal capacity, so the following condition has to be satisfied

$$
F \leq n_{i} N_{i}
$$

where $F$ - load the pile is to carry, $N_{i}$ - pile internal capacity, $n_{i}$ - factor of safet.

Displacements of a pile formed in soil cause passive soil pressure on the pile periphery and below its base. An increase of load applied to a pile causes an increase of displacements and, as a result, soil resistance increases. The maximum load a pile can carry is defined by its bearing capacity, actually the capacity of the pile-loaded soil connection. Following the terminology adopted in this article, this capacity defines the external capacity of a pile. This is because its magnitude is basically affected by the pile outer surface which is a pile-soil contact surface. The condition of pile safe work takes the form

$$
F \leq n_{e} N_{e}
$$

where $F$ - as in previous cases is a load a pile is to carry, $N_{e}$ - pile external capacity, $n_{e}$ - factor of safety.

The surface of the periphery of a pile placed in soil also makes up the soil-grout contact surface. In actual reality then, the determination of pile bearing capacity and its displacement results from a solution of the contact problem with three contact surfaces. Each of these surfaces is defined by different couples of materials: concrete-grout, grout-steel and soil-grout.

It is important that deformation on contact surfaces of materials which adhere to one another can be different and depends on the properties of those surfaces. Due to respective slip of particular couples of materials on the contact surfaces the foundation-pile-soil elements undergo respective displacement. The total displacement is then a sum of all displacements (including their sense). However, because of different properties of particular contact surfaces specific restrictions should be imposed on each component of displacements vector (slip). Consequently, to ensure effective and safe work of a pile loads and displacements must be restricted by inequalities

$$
\begin{gathered}
F \leq n_{e} N_{e} \leq n_{i} N_{i} \leq n_{c} N_{c} \\
w_{c} \leq m_{c} w_{c}^{l}, \quad w_{i} \leq m_{i} w_{i}^{l}, \quad w_{e} \leq m_{e} w_{e}^{g r}
\end{gathered}
$$

where $w_{c}, w_{i}, w_{e}$ are values of slip on foundation-pile contact surface, reinforcement-cement grout contact surface and range of pile slip in soil. The pile slip in soil in particular can be a measure of the soil load that is transferred to soil through strengthened foundation. $m_{c}, m_{i}, m_{e}$ are factors of safety. Variables with the "l" superscript denote respective limit values.

The proposed design conditions apply to foundation-pile-soil structure, while in structures supported on many such elements not even minor displacements are allowable for utility or technological reasons. For any foundation-pile-soil system the following condition must also be fulfilled

$$
w_{t} \leq m_{t} w_{t}^{l}
$$

where $w_{t}$ is a total displacement of foundation-pilesoil structure, $m_{t}$ is a factor of safety, $w_{t}^{l}$ is a limit displacement of structure (building). This condition, 
however, is sufficient only in the case of uniform displacements of each element of foundation-pile-soil structure supporting the superstructure.

Superstructures are often sensitive to non-uniform displacements of supporting elements. Even minor differences between displacements of particular supporting elements can result in limit conditions and cracking in a building. Therefore the following condition should be fulfilled

$$
w_{c}^{\max }-w_{c}^{\min } \leq m_{r} \Delta w^{l}
$$

where $w_{c}^{\max }, w_{c}^{\min }$ are maximum and minimum displacements from among all displacements of foundation-pile-soil structure, $m_{c}$ is a factor of safety, $\Delta w^{l}$ is an allowable difference between displacements of supporting elements specified for a given structure.

The article presents the results of experimental verification of the first process described above which has a major effect on modelling low-pressure injection piles anchored in existing foundations and transferring loads from foundations to lower, stiffer soil strata. The experiments concern determining the bearing capacity in the foundation-pile contact area and deformations of both elements in this area.

\section{PILE ANCHORAGE IN FOUNDATION}

If the anchorage is not properly executed, the pile that strengthens the existing foundation becomes useless. Pile-foundation connection must have the capacity of transferring the design load from the foundation onto the pile and then to the lower layers of soil.

The papers dealing with piles, quoted in the literature, focus mainly on their deformation in soil [8]-[18], providing the results of experiments and analysis of pile-foundation interaction rather infrequently. This scope of the problem was undertaken in several papers presented at ISM conferences [19]-[21]. This subject is also discussed in [22]-[24]. Those experiments concentrated on piles anchored in concrete blocks that modelled concrete fundations constructed on micropiles. During strengthening the existing foundations the pile is formed in a hole which is drilled earlier through the foundation constructed in different historical peridos from various materials. Apart from bearing capacity of such a connection significant is also the deformation of both materials from which the pile and the foundation is constructed on their contact surface.

The simplest and most frequently employed technology of strengthening the existing foundations is to drill a hole through the foundation and then drive a pile in both the foundation and soil. If the foundation displacements due to insufficient pile bearing capacity are out of control, loads are transferred onto pile through skin friction on the pile-foundation contact surface (on pile periphery). Since there are no material constants and parameterization of the mechanical processes on the contact surface this approach is intuitive rather than factual.

To verify the usefulness of the technology of connecting pile with foundation presented above a series of tests have been performed to examine the failure process of such a connection focusing on the basic materials of which the foundations are made and under various loading conditions. The experiments were conducted on specimens that modelled the real geometry of foundations in the foundation-pile interaction range.

\subsection{PUSHING THE PILE INTO FOUNDATION}

The first tests were conducted in 2011 [2] in order to verify the effectiveness of such a connection used alternatively to strengthen the foundations of the IKEA store in Cracow (Fig. 3a). Fig. 3b shows the original project - the pile was anchored directly in the column.

The tests were conducted on concrete specimens $(\mathrm{C} 20 / 25)$ of dimensions $50 \times 50 \times 50 \mathrm{~cm}$ and $50 \times 50$ $\times 60 \mathrm{~cm}$. The influence of reinforcement was included by concreting the specimens in a frame made of welded steel L-sections $25 \times 25 \times 3 \mathrm{~mm}$. In order to check the effect of reinforcement on the connection bearing capacity, part of the specimens were prepared without reinforcement. After 28 days of concrete curing, the specimens were drilled centrically in the same conditions as on a construction site with a drill of $225 \mathrm{~mm}$ external diameter. In the drilled space after the removal of the core, a pile was formed. The pile was formed from cement grout (w/c ratio of 0.5$)$ and reinforced with a cage made of $16 \mathrm{~mm}$ diameter ribbed steel bars. After another 28 days strength tests were performed. The scheme of load application is shown in Fig. 4, substituting the effect of pile action in soil. The loading process was continued to the loss of cohesion on the pile surface (pile pulled out of specimen). In total, the tests were performed on 40 reinforced specimens and 30 specimens with no reinforcement.

The form of damage was the same in all seventy specimens. In Photo 1, cracking of a specimen and pile dislocation are shown after the load reached the value which caused pulling the pile out of specimen. Photo 2 presents the form of damage after the reinforcement is 


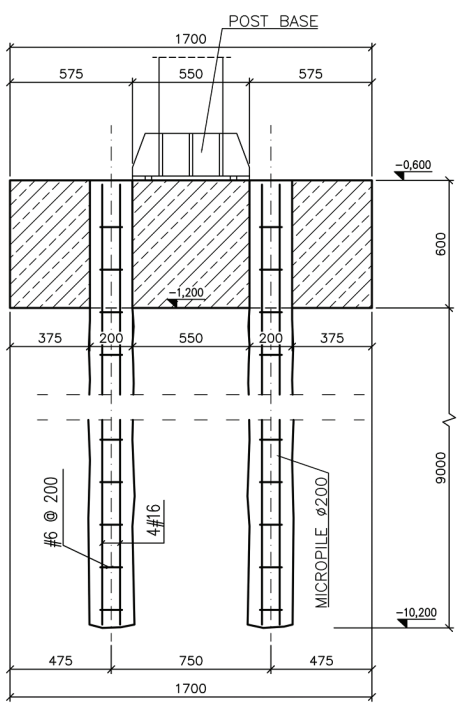

Fig. 3a. Alternative pile anchorage in foundation

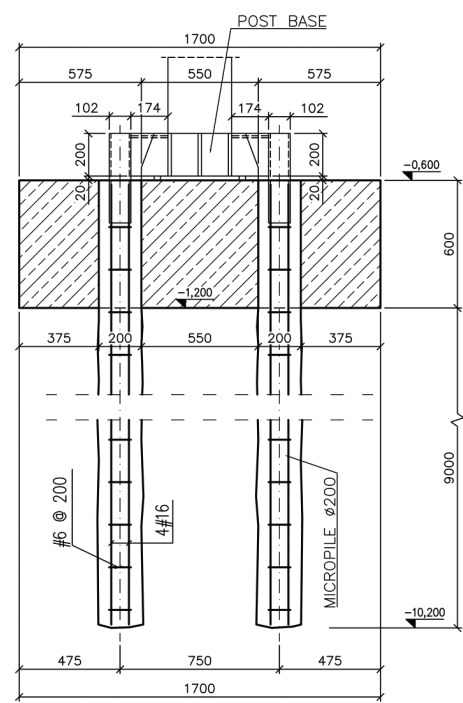

Fig. 3b. Pile anchorage in post through steel construction [6]

split. The adhesion on the contact surface is totally lost. The separated pile rests loose in the specimen hole. In none of the specimens was the pile failure observed. The growth of positive transverse strains in the pile pushed into the specimen causes a positive strain state in the concrete part of the specimen. After the positive strain in concrete reaches the limit value, failure of test-piece modelled foundation is observed.

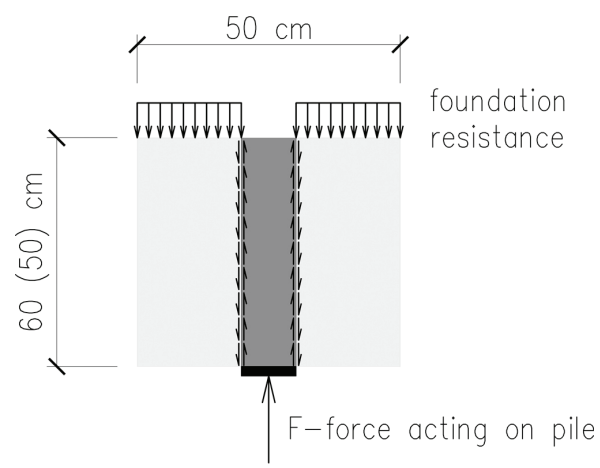

Fig. 4. Loading of specimens
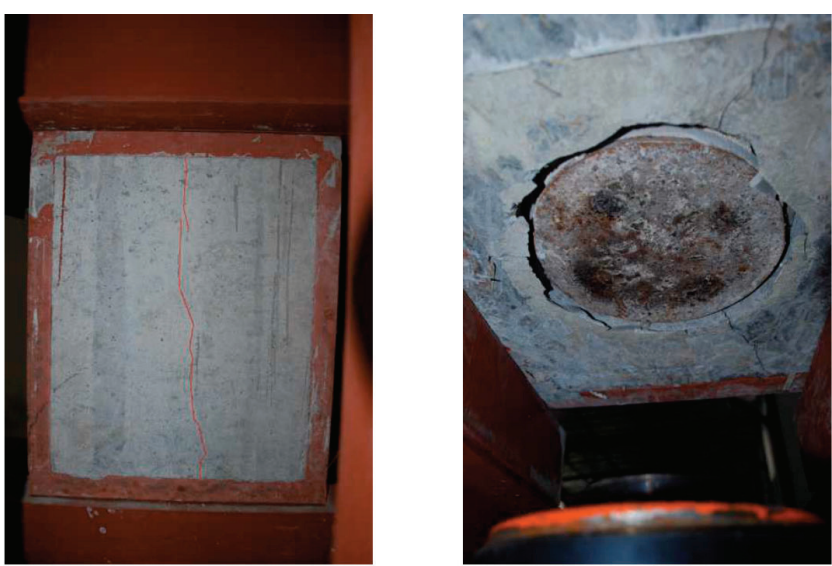

Photo 1. Specimen cracking and pulling the pile out of specimen
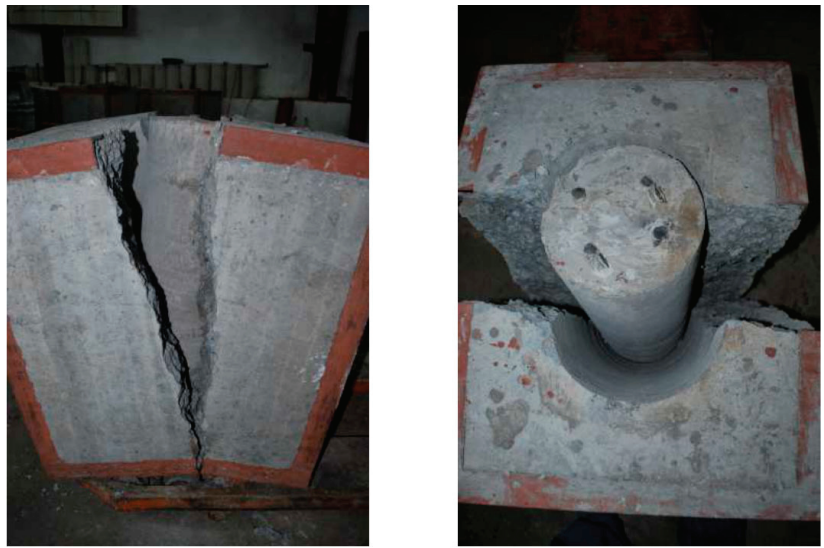

Photo 2. Form of specimens failure

What decided of the bearing capacity of pile anchorage in the foundation was the foundation bursting resistance. It should be noted that the original solution (anchorage of piles directly in a column) does not change the form of failure, i.e., foundation bursting. Not only the forces acting on piles but also the deformations of piles in holes drilled through the foundation remain unchanged. The presented study has been done for contract purposes, therefore the test program was limited to the testing of the bearing capacity of this kind of anchorage.

The wide application of low-pressure injection piles for the purpose of strengthening the foundations of historic buildings makes it necessary to verify the admissibility of technology of anchorage in foundations constructed in different historical periods. In the past, the foundation of buildings was built as foundation walls with or without corbel. At the beginning, foundation walls were built from local stone, then bricks on different types of grout. In the past century foundations were made from concrete and reinforced concrete. Particularly in reinforced foundations strip footing and 
spread footing was constructed. In these cases the length of anchorage was important because of limited vertical dimension of these foundation elements.

In the experiments presented brick foundations [3] were modelled with specimens from modern solid brick class $15(\mathrm{MPa})$ on cement-lime mortar BAUMIT MM50. Two brick wall thickness was adopted, which at correct bricklaying corresponds to $52 \mathrm{~cm}$. The height of specimens was restricted to seven brick layers, which also corresponds to $52 \mathrm{~cm}$. Along the length of the wall toothings were preserved and the minimum length of the sample was $53 \mathrm{~cm}$. Thirty-seven specimens were tested which is regarded as small statistical sample.

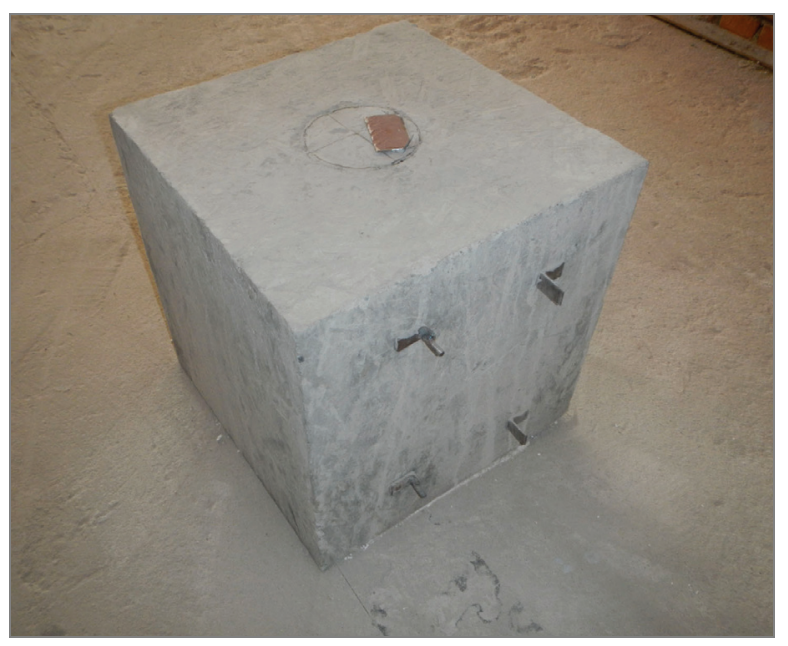

Photo 3. Specimen modelling foundation made of concrete

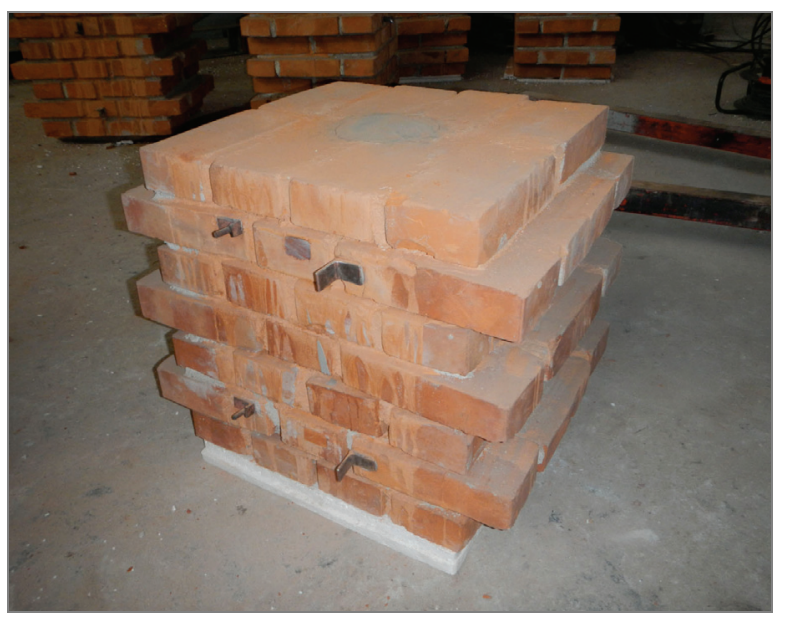

Photo 4. Specimen modelling foundation made from brick

In the last century, concrete was often produced on the construction site by volumetric dosing. This kind of concrete can be classified as $\mathrm{C} 12 / 15$, which is the lowest class of structural concrete commonly found in existing buildings. This is why this class of concrete was used in the tests. The tests [4] were conducted on twenty-eight specimens $50 \times 50 \times 50 \mathrm{~cm}$ made of concrete class $\mathrm{C} 12 / 15$ which was delivered from a concrete plant. In both concrete and masonry specimens, after curing $150 \mathrm{~mm}$-diameter holes were drilled (Photos 3, 4). Piles of this diameter are commonly used to strengthen the foundation, hence this hole diameter was selected. In drilled holes, piles were formed. Inside the holes piles reinforced with four bars $14 \mathrm{~mm}$ in diameter were installed. Round plain steel stirrups $6 \mathrm{~mm}$ in diameter were spaced every $20 \mathrm{~cm}$. The piles were made from cement grout of $\mathrm{w} / \mathrm{c}$ ratio of 0.5 , on the base of cement CEM II/B-M(V-LL)32,5 R, from Rudniki cement factory.

As in previous experiments the loading scheme was adopted as shown in Fig. 4. Load was applied until pile-foundation adhesion loss. Apart from the measurement of load and displacement (axial displacement of jack piston) measurements were taken of displacements at fixed bases as shown in the schematic diagram below (Fig. 5).

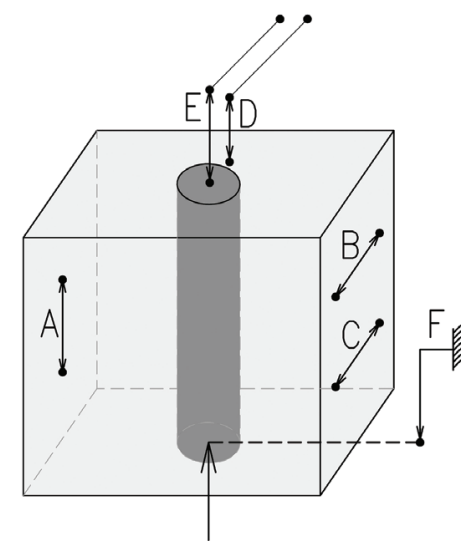

Fig. 5. Location of displacement sensors

Failure propagation process, and in consequence macrocracks and failure of elements made of brittle materials such as concrete, brick, mortar and grout are highly dependent on the loading application program. In the tests, loads were applied using hydraulic jacks with a given initial velocity of the piston. Different resistances of specimens and characteristics of hydraulic jacks used in experiments accounted for the displacements of the pile head. The displacements of pile heads measured during the tests on individual concrete specimens are shown in Fig. 6a. Figure 6b illustrates real displacements of piles heads for five selected specimens modelling brick foundation.

Such displacements of pile heads were accompanied by time variable loads controlled by the resistance on the pile-foundation contact surface. For concrete specimens this relationship is shown in Fig. 7 and for brick specimens in Fig. 8. The same nature of the process is clearly seen. 


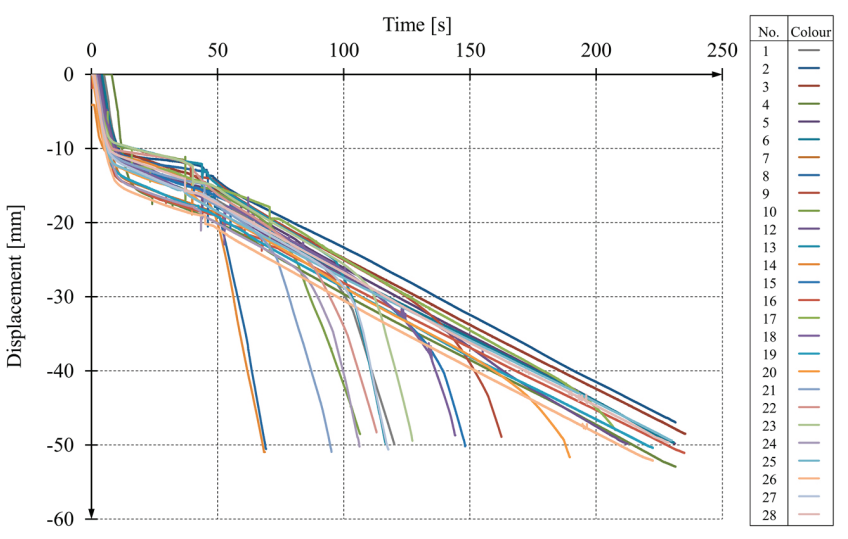

Fig. 6a. Changes of displacements of pile heads in selected concrete specimens

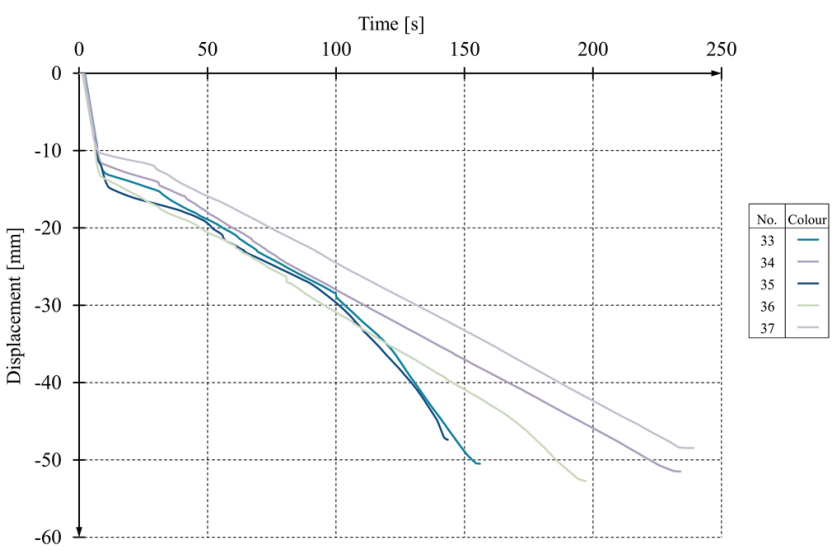

Fig. 6b. Changes of displacements of piles heads in brick specimens
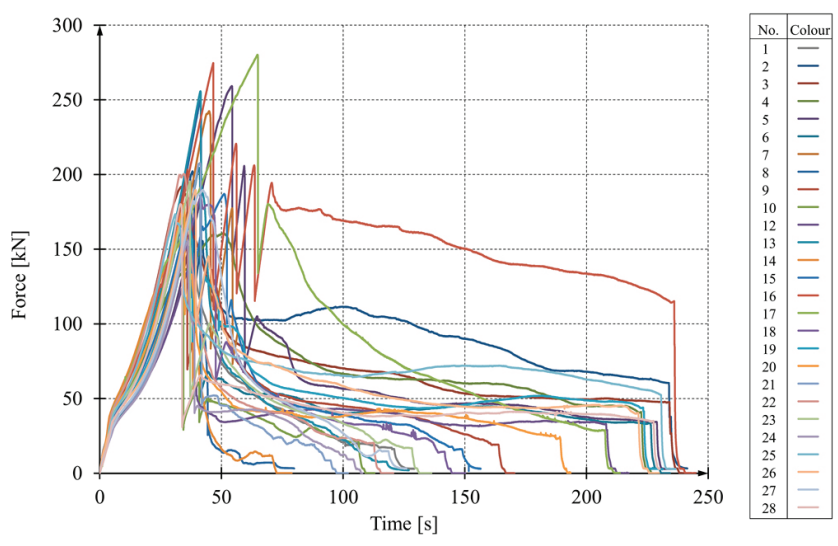

Fig. 7. Changes of load transferred by pile-concrete specimen anchorage

The obtained results indicate that at the initial stage of load application linear and similar to each other increments of load occur in all specimens. The first microcracks in the contact area, accompanied by acoustic effects, are followed by a decrease of load increment rate. The curves diverge and a scatter of results increases. The field of microcracks intensifies and spreads over an increasing large space. Diver- gence between displacements of both parts of the specimens in the contact surface area also increases. The slip on the contact surface increases.
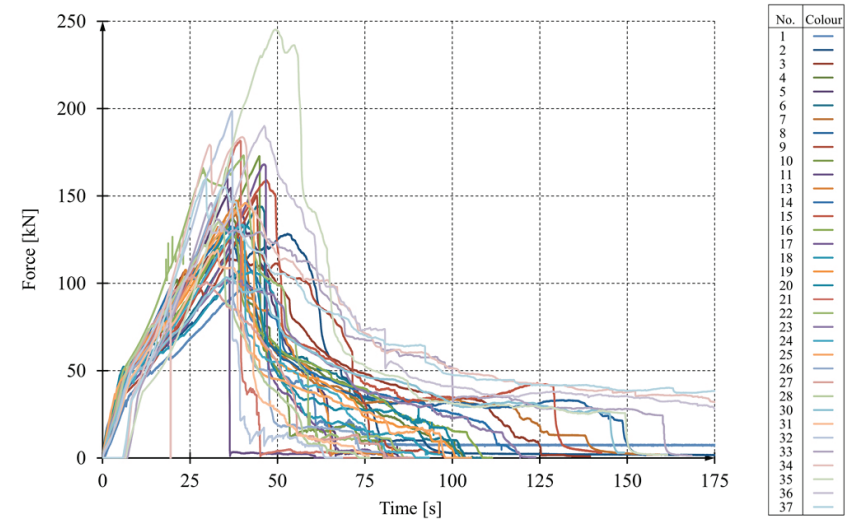

Fig. 8. Changes of load transferred by pile-brick specimen anchorage

The final effect is the formation of macrocracks and fractures observed on the external surfaces of specimens (Photos 5,6). The load that can be transferred by the contact surface begins to drop violently. At this stage the scatter of the test results is the highest. This state is basically affected by nonuniform propagation of microdamage. Both microcraks propagation rate and their distribution in the area tested are different in particular specimens. Deformation process on the contact surface is illustrated in Figs. 9, 10 in which simultaneous distribution of force together with pile and foundation displace-

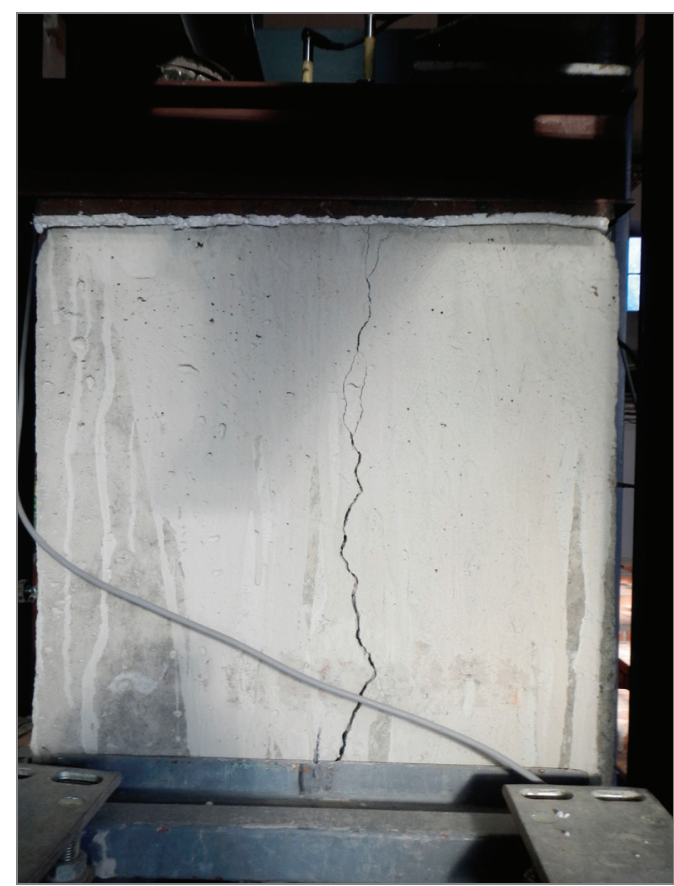

Photo 5. Macrocracks at final stage of force application observed in foundation specimen made of concrete 


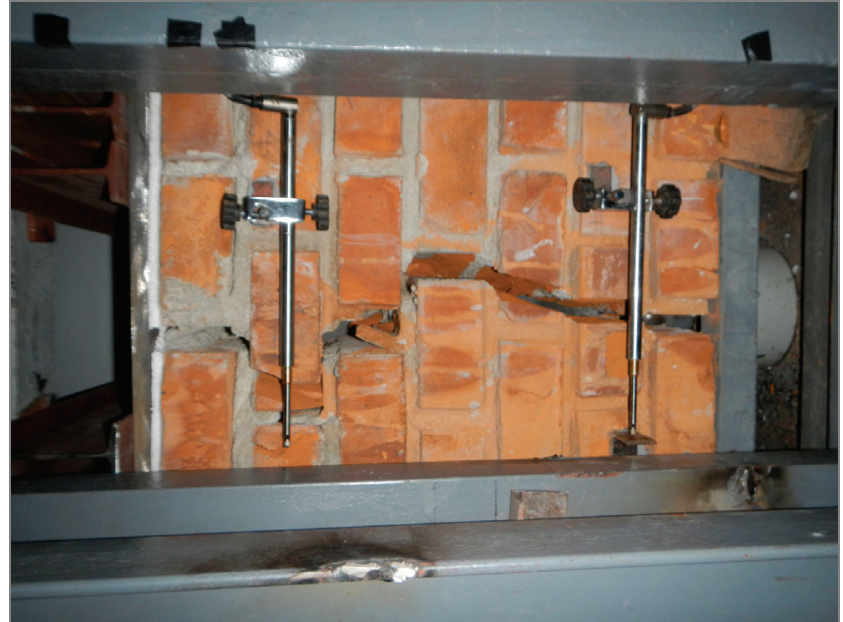

Photo 6. Macrocracks at final stage of force application observed in foundation specimen made of bricks

ments on the contact surface are shown for selected concrete and brick specimens. At the initial stage the displacement of loaded pile head (curve F in Fig. 9) increases faster than the displacement of its free end (curve E). The pile is shortened and as a result its diameter enlarges. The damage process of the connection begins and the difference between the displacements of the pile free end (curve E) and corresponding surface of the specimen modelling foundation (curve D) widens. This difference indicates a slip on the contact surface of the two materials, i.e., concrete and grout of the pile in Fig 9 and masonry wall and grout in Fig. 10. As the slip increases, pile relaxation is observed and the difference between the values on curves $\mathrm{E}$ and $\mathrm{F}$ decreases.

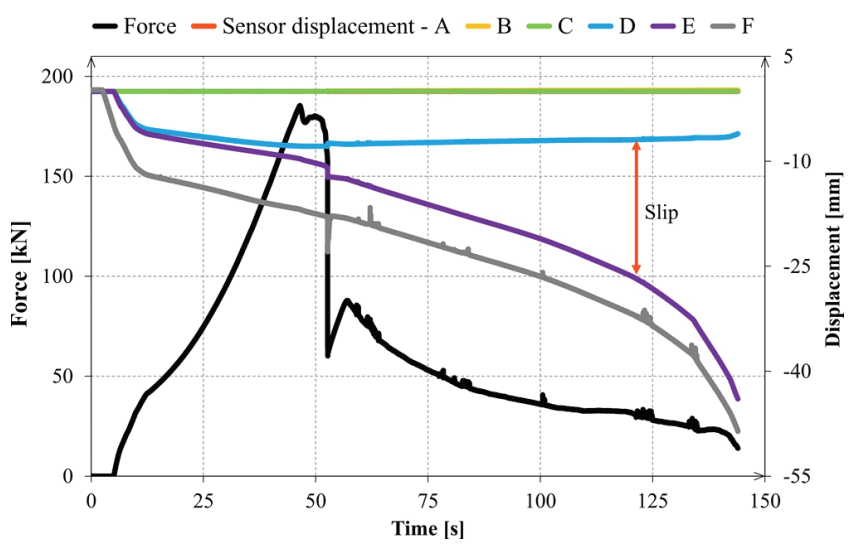

Fig. 9. Changes of displacements in a selected concrete specimen

The further from the contact surface the smaller the deformation of specimens. The sensors fixed on specimens external surfaces did not detect any important changes. Only the sensors through whose base passed the surface destroying specimens indicated a rapid increase of displacement values. In Figs. 11a and $11 \mathrm{~b}$, changes of displacements of concrete specimens are compared, when the crack damaging a sample was located in the sensor base. The form of failure for all specimens remained the same. The foundation part cracked and the pile was pulled out of the specimen. Photo 7 illustrates the results for concrete foundation, Photo 8 the results for masonry foundation.

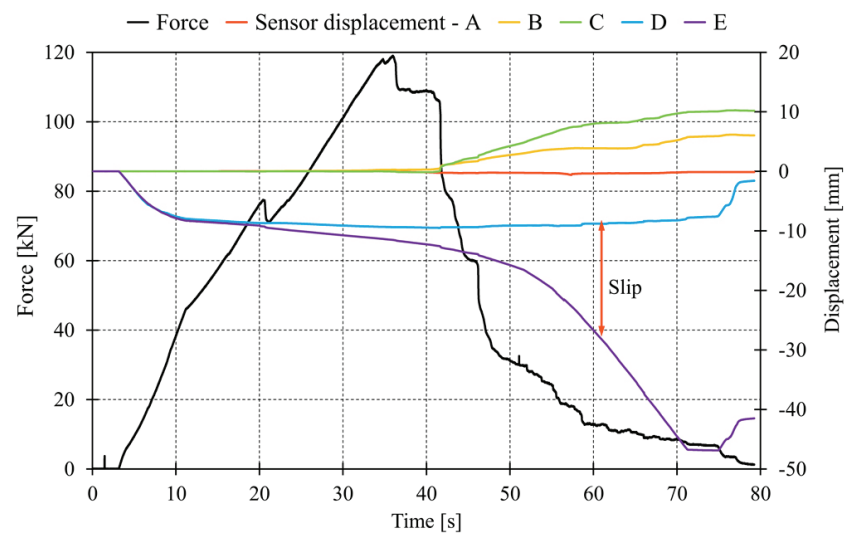

Fig. 10. Changes of displacements in a selected brick specimen

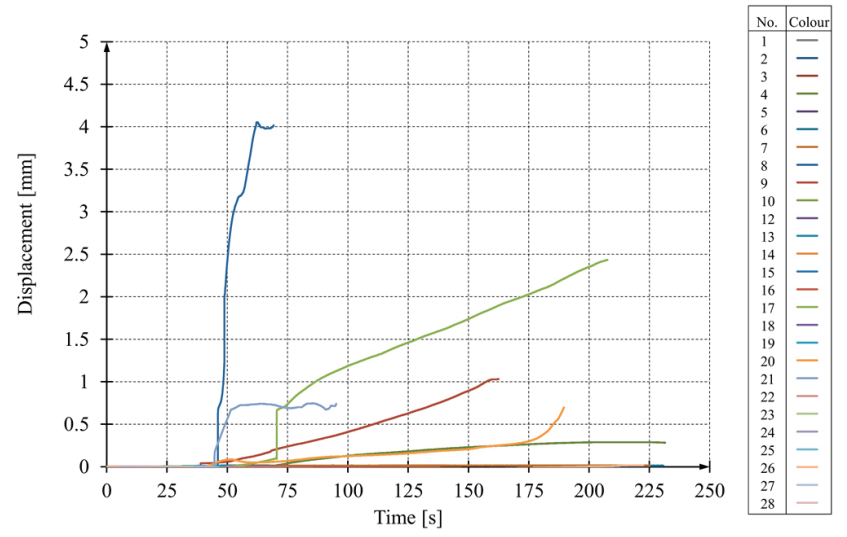

Fig. 11a. Changes of displacements measured on base B (Fig. 5)

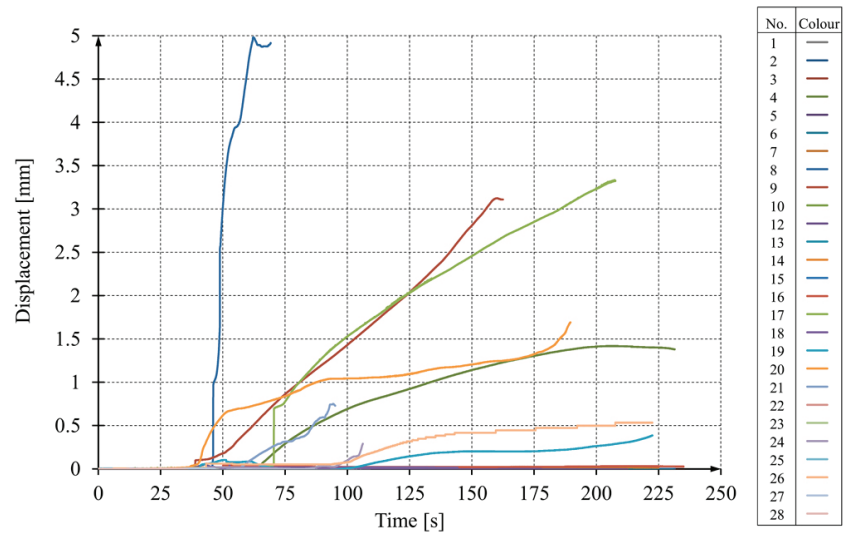

Fig. 11b. Changes of displacements measured on base $\mathrm{C}$ (Fig. 5) 


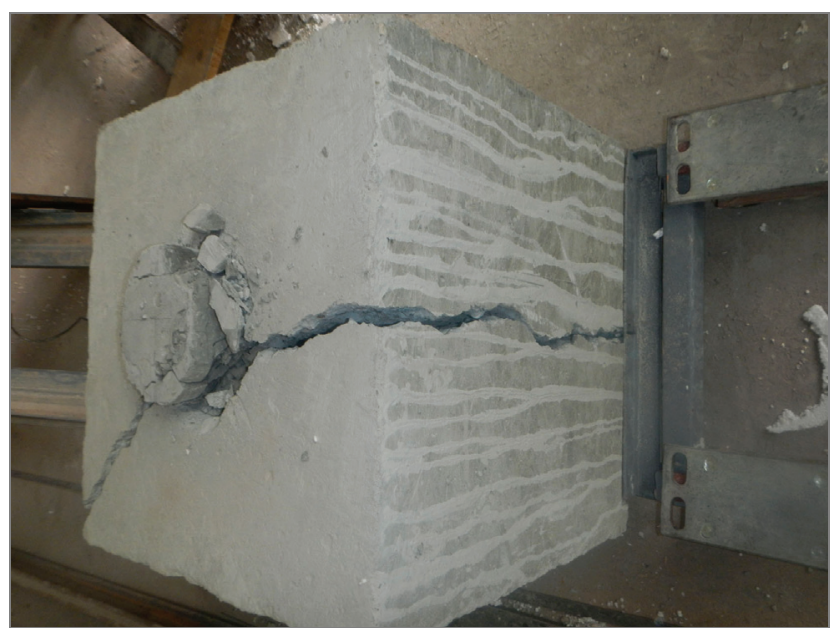

Photo 7. Form of concrete specimens failure

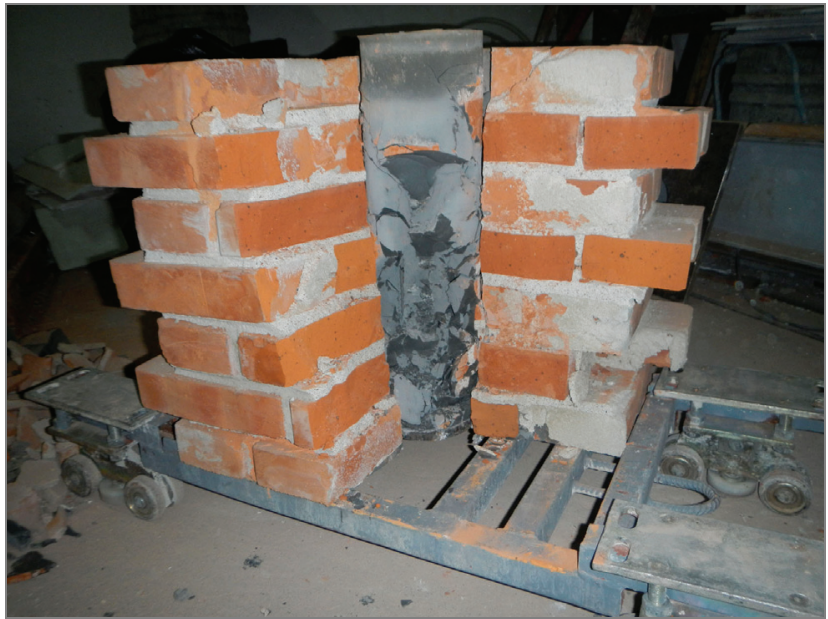

Photo 8. Form of brick specimens failure

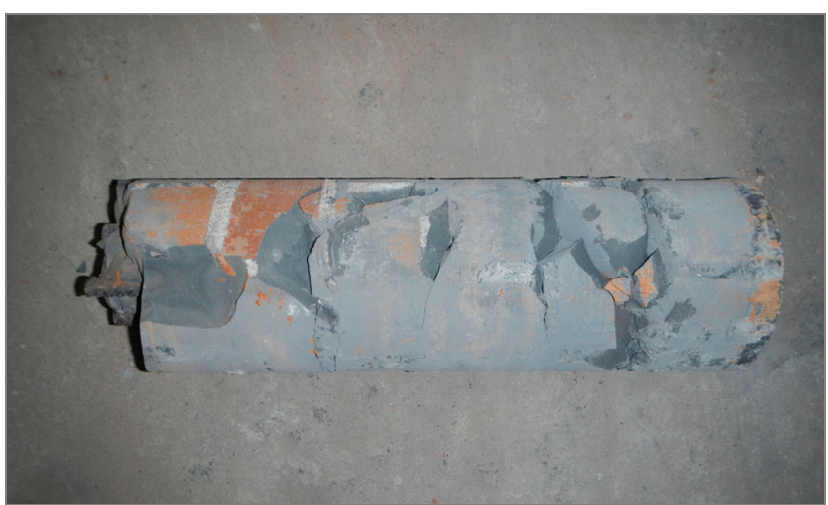

Photo 8a

The results of the tests confirm that the most significant influence on pile-foundation connection damage is exerted by positive circumferential strains in the foundation caused by circumferential strains in pile in compression. On reaching the limit value these strains cause the formation of a macrocrak followed by foundation failure. In concrete foundation the pile remains intact (Photo 9). In masonry foundations horizontal cracks form, overlapping the periodic structure of brick layers and mortar (Photo 8). This effect is a result of different adherence and deformability of bricks and mortar pre-bonded with the pile.

The difference between longitudinal displacement of a pile free end and the corresponding surface of the foundation part is a measure of the total slip on the pilefoundation contact surface. The slip values result from the difference between the readings of sensors $\mathrm{E}$ and $\mathrm{D}$. In Fig. 12, changes of the slip taken in particular load tests have been listed for all the concrete specimens tested. The slip changes for masonry specimens are shown in Fig. 13.

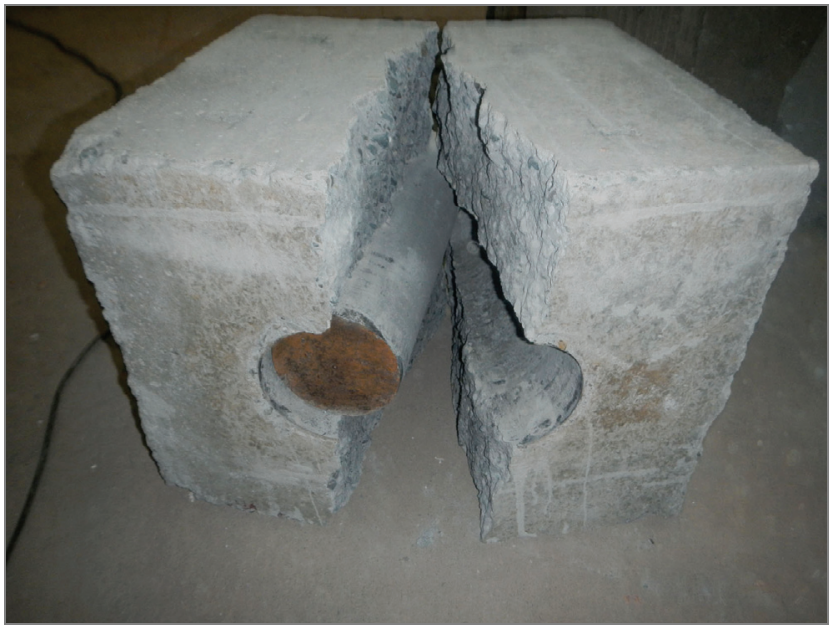

Photo 9. Pile after concrete specimen failure

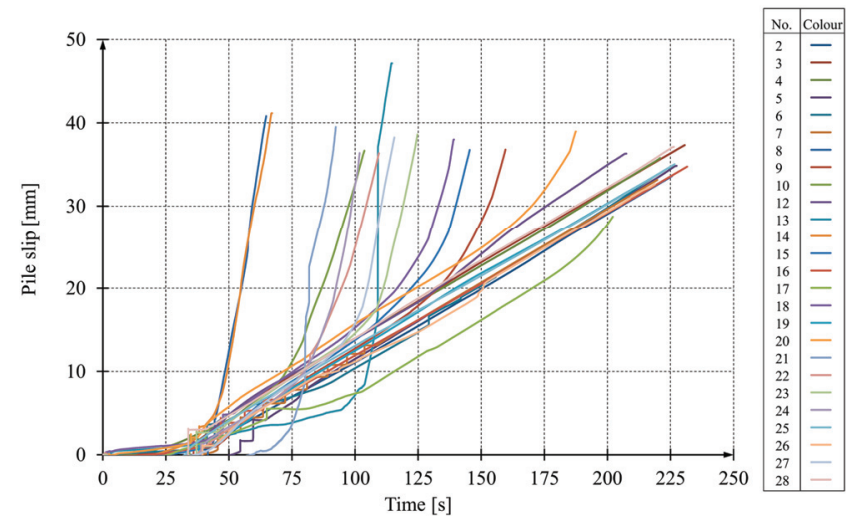

Fig. 12. Pile slip during loading of concrete specimen

At the initial stage, a minor linear change in the slip was observed, which was followed by quite a rapid slip increment, although the change practically remained linear. At the unstable stage the process was nonlinear. The slip increment rate increased exponentially, to end this stage by pile being pushed out of the foundation. 


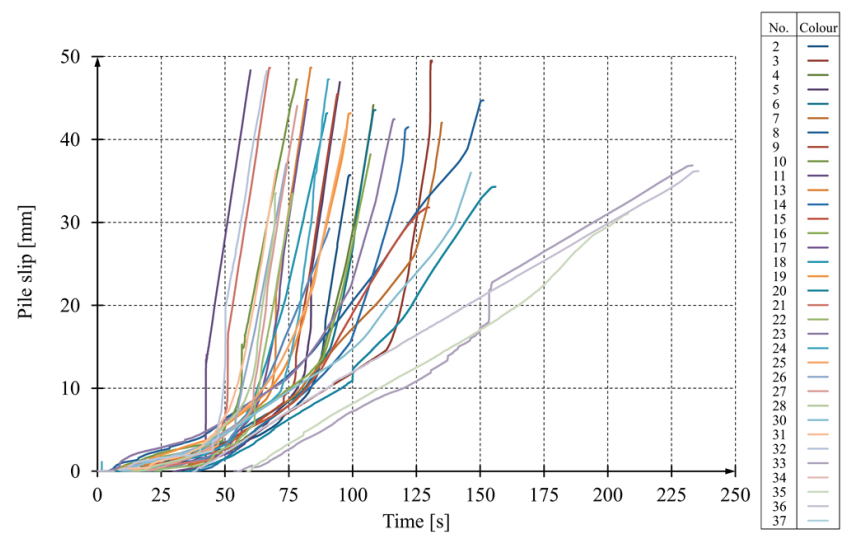

Fig. 13. Pile slip during loading of masonry specimens

The pile-foundation anchorage bearing capacity was defined as the greatest force that is able to transfer the pile-foundation connection while loaded. The value of this force is a random event. In the experiments presented the number of specimens characteristic of a small sample allows the determination of statistic parameters.

Adopting as a basis the normal distribution for values obtained from experiment, the parameters of probability distribution were calculated. The scatter of test results makes it necessary to specify for design purposes a guaranteed value.

It has been established that the probability of occurrence of breaking force lower than a guaranteed value is not higher than $5 \%$. From the practical point of view it is convenient to use values referred to a unit of area. It has then been adopted that the strength of the connection is a breaking force referred to the contact surface.

In Fig. 14, probability distribution of the pilefoundation connection strength in all specimens tested is presented $(R)$. The summary of the results provides parameters basic from the engineering point of view: mean values, guaranteed at 5\% and standard deviation.

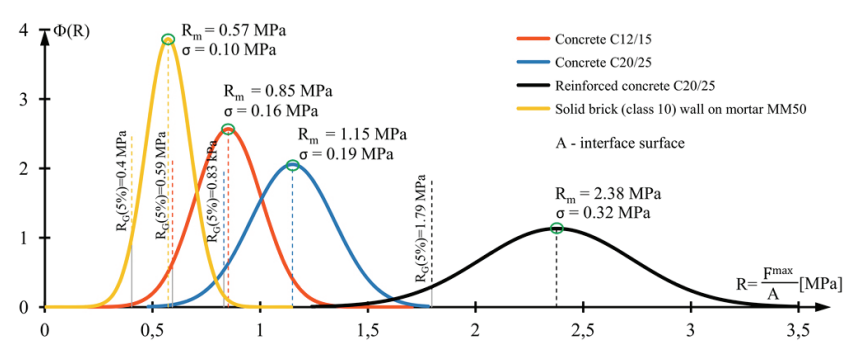

Fig. 14. Probability distribution of strength of connection between pile and the part modelling various types of foundations The following symbols have been adopted:

$F_{\max }$ is the maximum force obtained in experiment,

$R_{m}$ and $R_{G}(5 \%)$ are the mean and guaranteed values, respectively, at $5 \%$ strength of connection, $\sigma$ is a standard deviation, $A$ is the contact surface
The tests covered the total of 130 foundation specimens that modelled foundations made of solid ceramic brick and from concrete class: C12/15, C20/25 and reinforced concrete $\mathrm{C} 20 / 25$. The test results confirm intuitive knowledge. They revealed that foundations made from reinforced concrete have the highest anchorage strength. The placement of reinforcement in the foundation doubled the anchorage strength compared with the foundations of the same class of concrete but with no reinforcement. The lower the class of concrete the lower the bearing capacity of the anchorage. The lowest values of anchorage strength were obtained for masonry foundations. What is also noticeable is an increase of the standard deviation with an increase of anchorage bearing capacity. The dispersion of test results increases with an increase of strength.

\subsection{PILE PULLOUT OF FOUNDATION}

The results presented hitherto refer to the study of anchorage bearing capacity and deformation in cases of loads causing pushing the pile into the foundation. In engineering practice we often encounter loads that result in the pile pullout of the foundation. The results of experimental verification of such a case of loads applied to concrete and masonry foundations are presented in [5].

To make a qualitative and quantitative comparison of experiment results obtained for piles pushed into the foundation with those obtained for pulled out piles analogous specimens were prepared. Specimens of the same size as before made from currently manufactured solid brick (class 15) on BAUMIT MM50 cement-lime mortar modelled masonry foundations. 32 specimens were prepared in such a way as to conform to the requirements of a small statistical sample.

For the same reasons concrete foundations of concrete class $\mathrm{C} 12 / 15$ were made. This class of structural concrete is the lowest and at the same time possible to make on a construction site, and often found in existing buildings. The tests were performed on 29 specimens of dimensions of $50 \times 50$ $\times 50 \mathrm{~cm}$.

In both masonry and concrete specimens after the curing period holes were drilled through foundation using a $150 \mathrm{~mm}$ diameter core. In the holes piles identical as in the case of pushing the pile into the foundations were installed but tips of SAS system thread bars were welded between the rebars to execute a force pulling out the pile (Photos 10, 11). 
The load was applied as shown in the diagram in Fig. 15. The load application continued until the loss of cohesion between the pile and the part modelling the foundation.

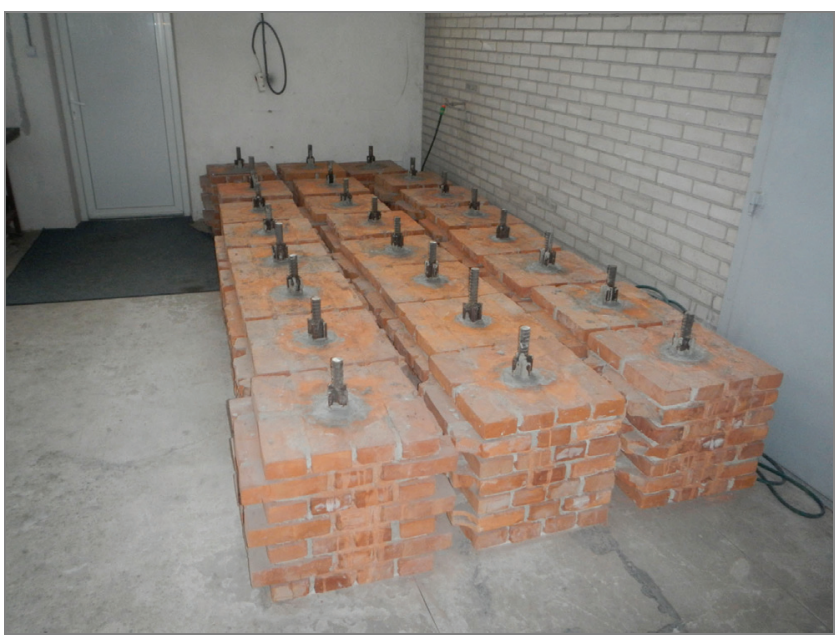

Photo 10. Test specimens modelling brick foundations

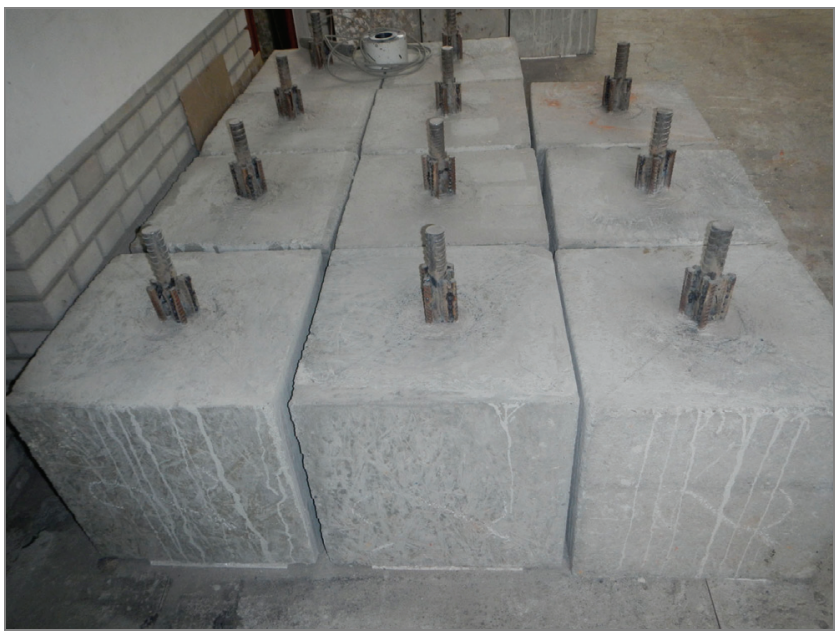

Photo 11. Test specimens modelling concrete foundations

Independent of measuring the magnitude of force and pile displacement (axial displacement of jack piston) measurements were taken of the displacements at fixed points as shown in Fig. 16.

The load in pile pullout tests was executed by the same jacks at a given initial velocity of their pistons as in the pile push-in tests. The measured displacements of piles heads in each masonry specimen are presented in Fig. 17a and for concrete specimens in Fig. 17b.

Such forced displacements of pile heads were followed by time variable forces depending on the resis- tance on the pile-foundation contact surface. For specimens made of brick this relationship is presented in Fig. 18a and for concrete specimens in Fig. 18b.

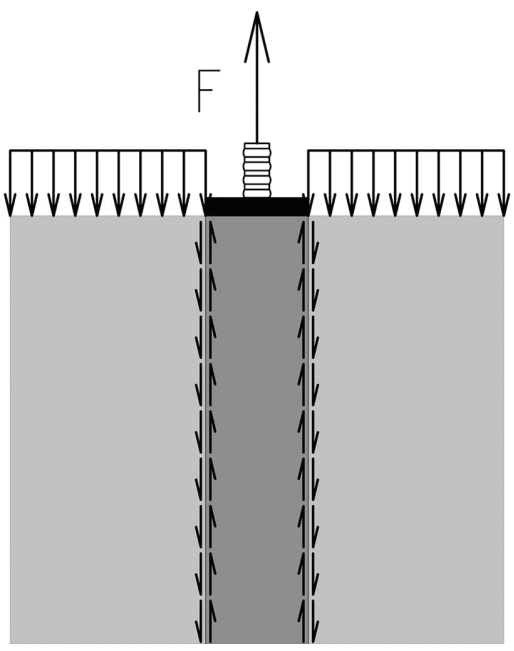

Fig. 15. Force application to specimens

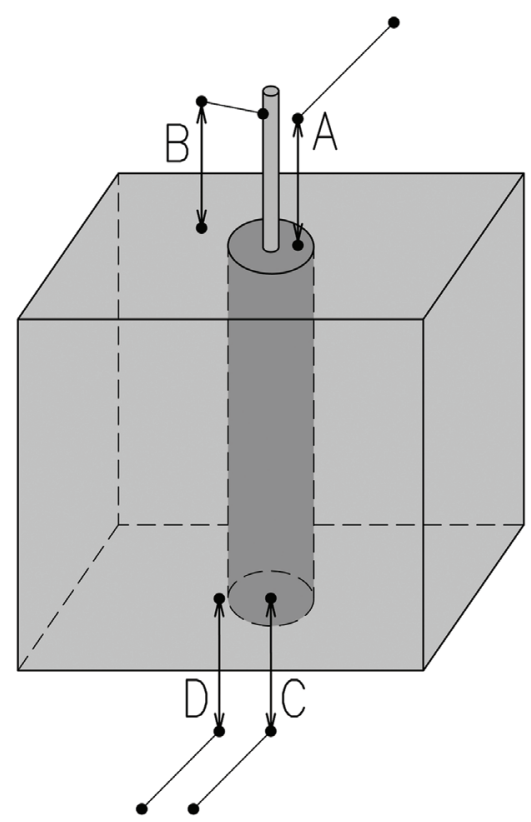

Fig. 16. Location of displacement sensors

In all the tests presented the same character of process is clearly seen. The test results indicate that at the initial stage of load application almost linear and similar in each step increment of load was observed. The first microcracks in the contact area, accompanied by acoustic effects, were followed by the force increment rate decrease. The curves diverged, dispersion of results increased. The field of microcracks intensifies and spreads over to an increasingly larger area modelling the foundation model. The discrepancy between displacements of both parts of specimen on the contact area widens. Consequently, the slip on the contact 
surface increases and, as a result, the pile slides out of the part of the specimen modelling the foundation (Photos 12b, 13).

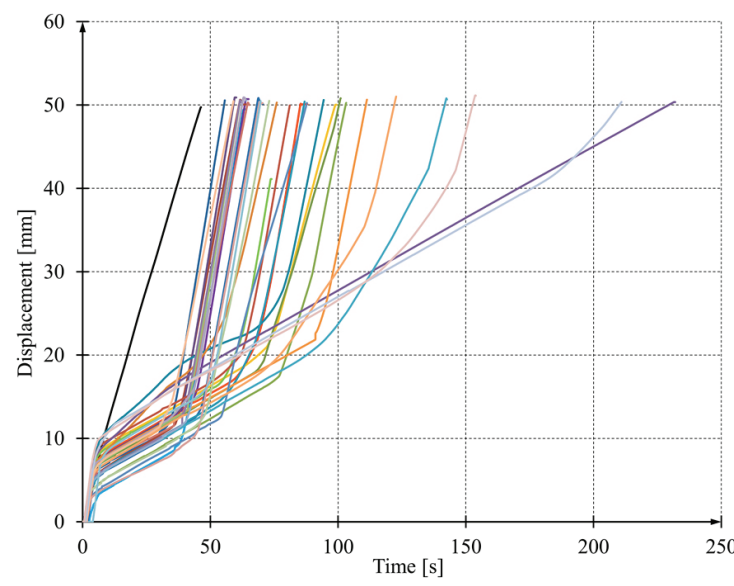

Fig. 17a. Pile head displacement change in masonry specimens

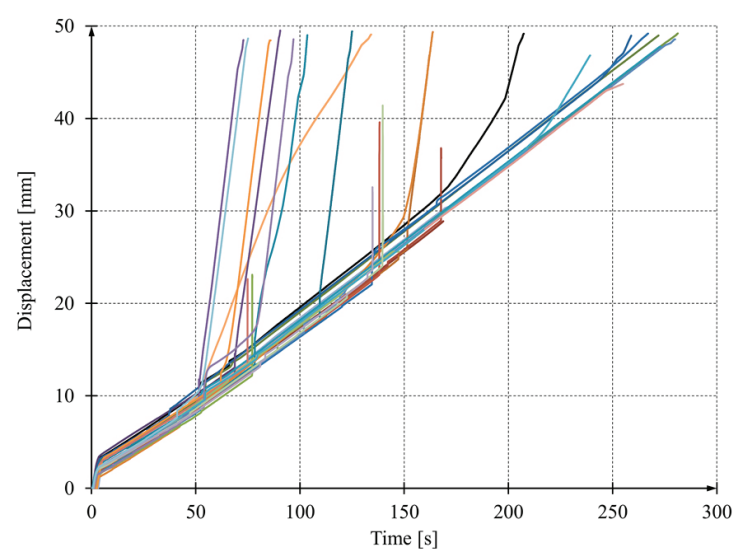

Fig. 17b. Pile head displacements change in concrete specimens
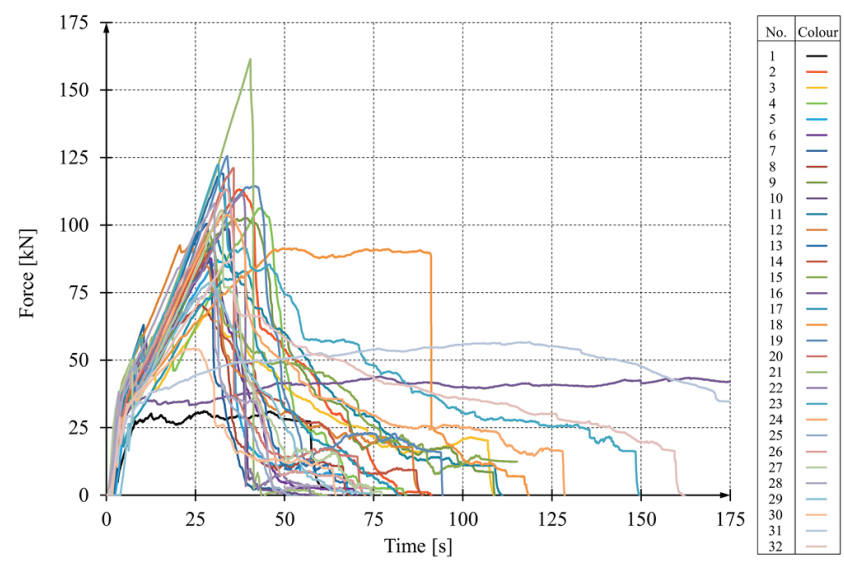

Fig. 18a. Force transferred by pile-masonry foundation anchorage over time

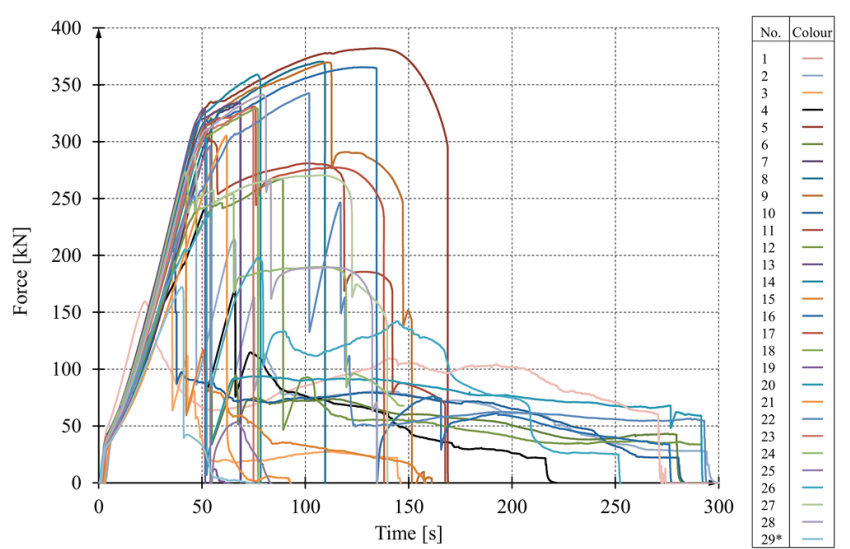

Fig. 18b. Force transferred by pile-concrete foundation anchorage connection over time

The final effect is the formation of macrocracks and fractures on the external surfaces of specimens (Photos 12a, 13). The force that can be transferred by the contact surface decreases rapidly and scatter of the test results is the highest. Similarly, this effect is accounted for by the non-uniform microdamage propagation, different intensity of microcracks development and their distribution in the area tested.

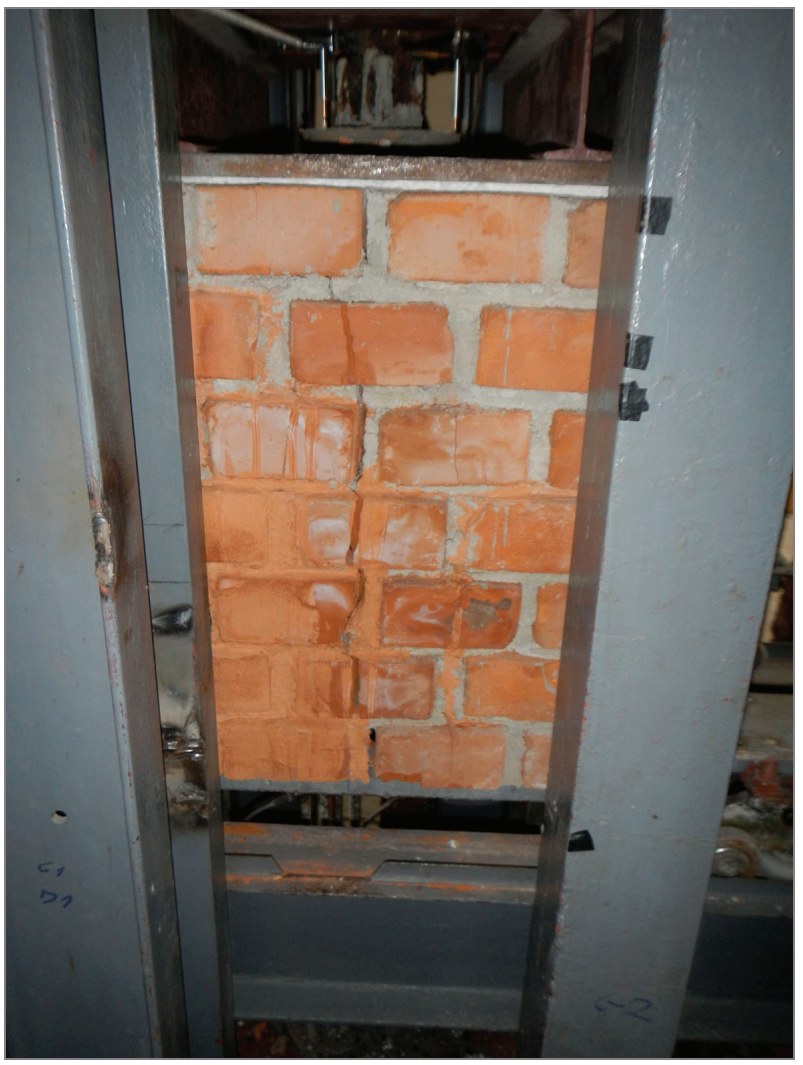

Photo 12a. Final fracture of brick foundation specimen 


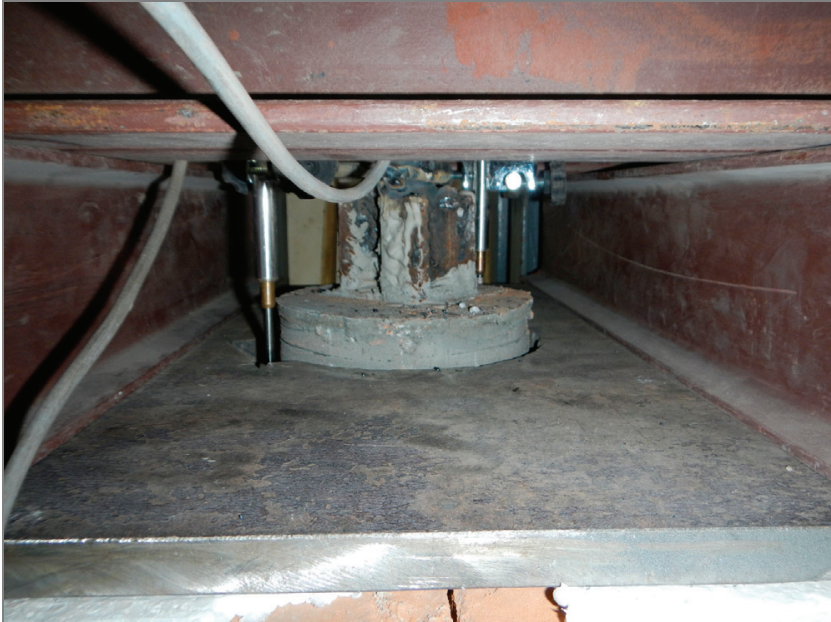

Photo 12b. Displacement of pile head in brick foundation specimen

It should also be noted that during pile pullout of the foundation the dispersion of results is much higher than during pushing the pile into the foundation. Violent decreases of the force and its subsequent increase resulting from the formation of microand macrocrakcs are indicated on graphs.

These kinds of damage reduce the connection area between the two materials and result in the failure of the foundation specimen and materials split.

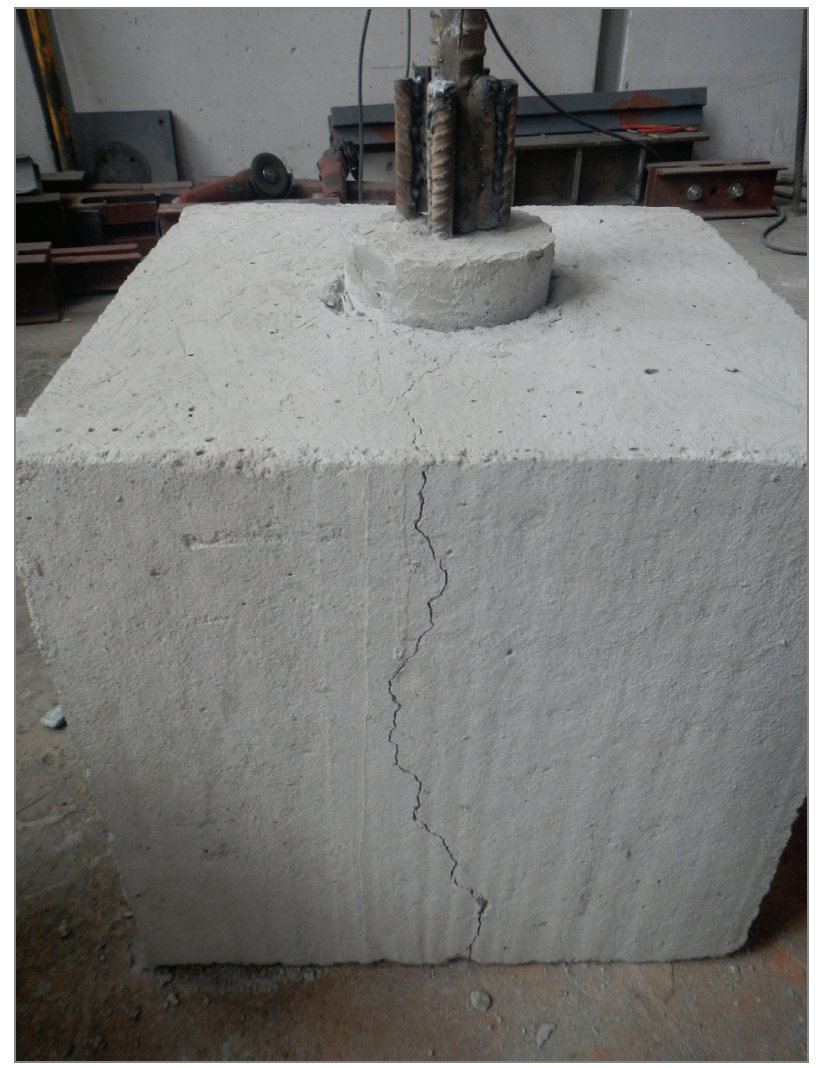

Photo 13. Concrete foundation specimen after the test
The results of pushing the pile into the foundation indicate positive peripheral strains on the connection surface as a factor that initiates the failure of pilefoundation connection.

On reaching the limit value these deformations cause a failure of the specimen foundation section. In concrete specimens the pile remained intact, while in masonry specimens additional horizontal cracks overlapping the brick layer-mortar period structure formed on piles. In the case of the pile pullout of the foundation also the effects of shearing forces acting on the free end of the specimen are clearly seen. Both in masonry (Photo 14) and concrete (Photo 15) specimens the pile free end was subjected to diagonal split followed by failure.

The form of failure of all specimens during pullout tests was the same as in push-in tests. The foundation section of specimens cracked and the piles were dislocated from the specimens (Photos 14, 15).

Considering the fact that the obtained results are random events, the statistical parameters were determined for respective mechanical values. Normal distribution was again adopted as a basis. In Fig. 19, the probability distributions of the strength of the pile-foundation connection in pullout and push-in tests are compared for concrete and masonry foundations.

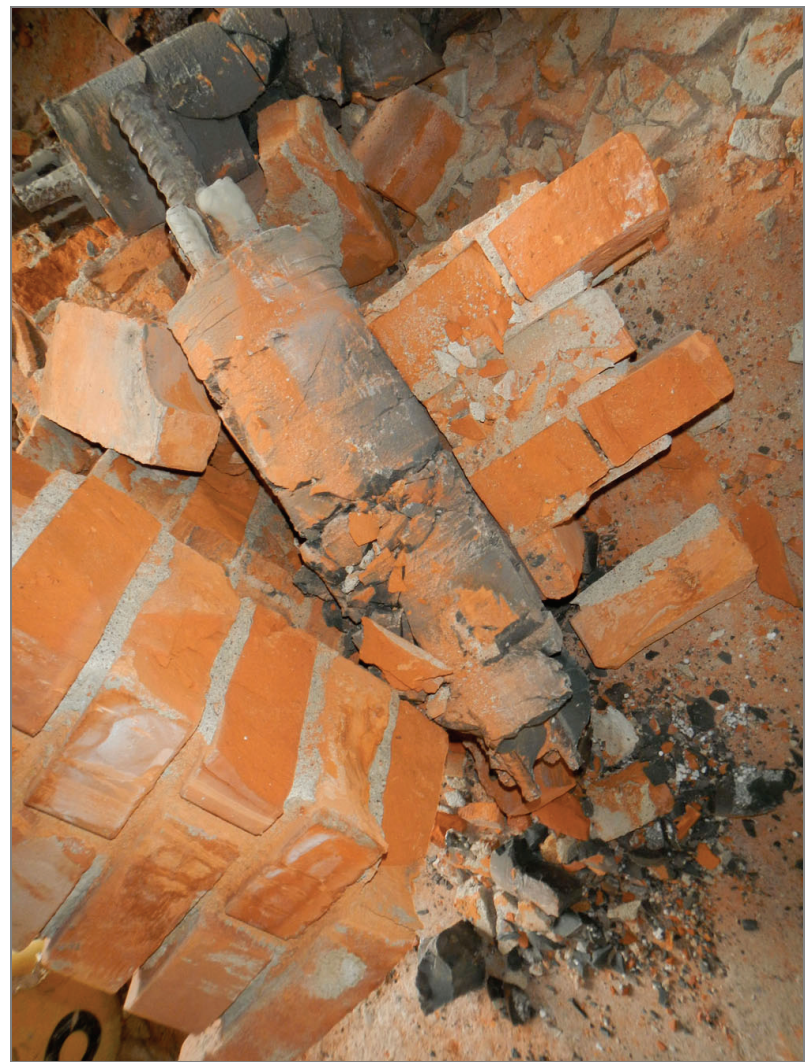

Photo 14. Damaged masonry foundation specimen 


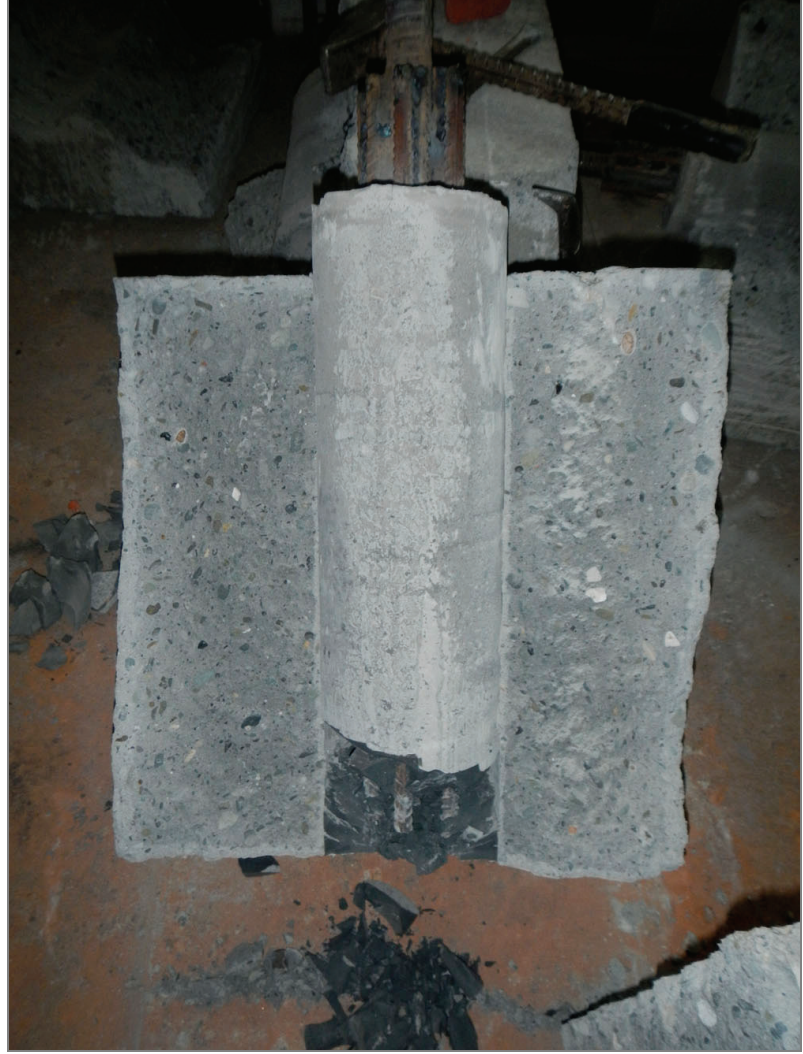

Photo 15. Damaged concrete foundation specimen

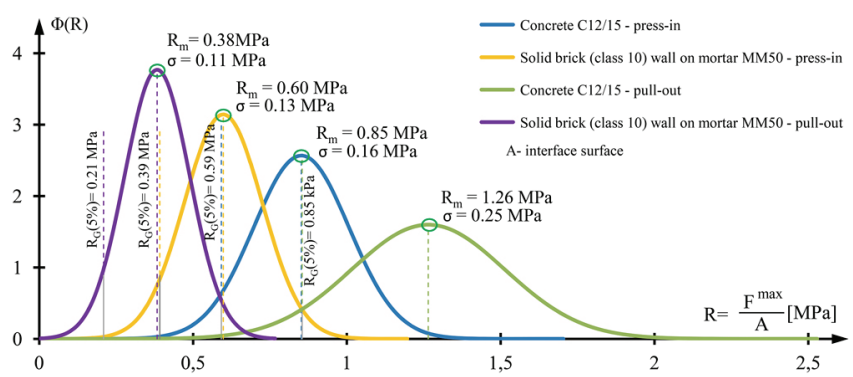

Fig. 19. Probability distribution of strength of pile-foundation connection for specimens tested Similar as before the following notation has been adopted: $F_{\max }$ is a maximum force obtained in experiment, $R_{m}$ and $R_{G}(5 \%)$ are the mean and guaranteed values, respectively, at $5 \%$ strength of connection, $\sigma$ is standard deviation, $\mathrm{A}$ is a contact surface

What is worth noting is that the mean and guaranteed values of strength of the masonry foundation-pile are higher for the pile push-in than for pile pullout. The reverse is true for concrete foundations: the strength of the connection for pile pushed into the foundation is lower than for pile pullout. The presented plots of probability distribution also indicate that the higher the strength of the connection the higher the standard deviation, which results in a wider scatter test results. The difference between mean and guaranteed values is also greater.
The displacements of piles and foundation specimen recorded in the contact area allowed the calculation of the differences, and consequently the slip on the load application plane and on the plane of specimens free edge, i.e., both ends of the piles. The results of tests presented in Figs. 20a and 20b for masonry specimens and in Figs. 21a and 21b for concrete foundation specimens indicate that the slip process starts within load application.

The slip is the most intensive on the surface on which the load is applied. The slip process on the pile free end is significantly slower and starts later.
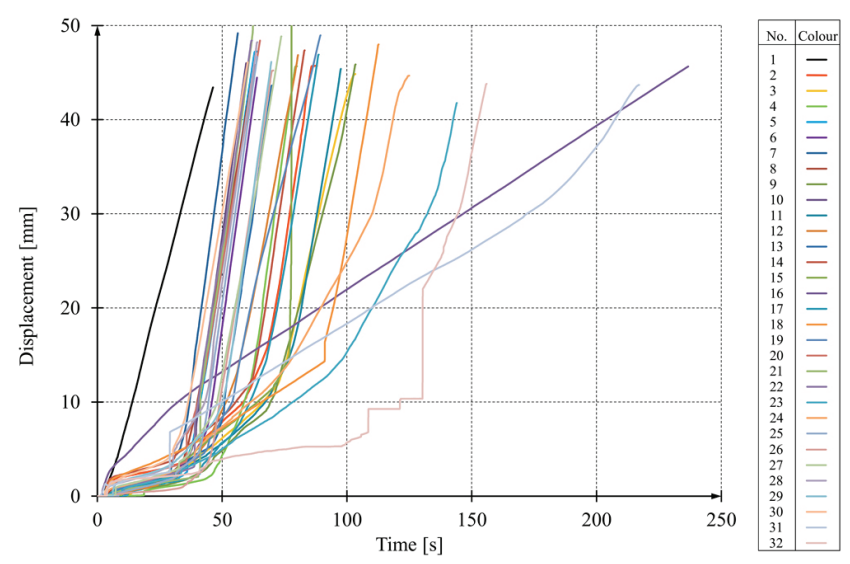

Fig. 20a. Slip on load application plane in masonry specimens
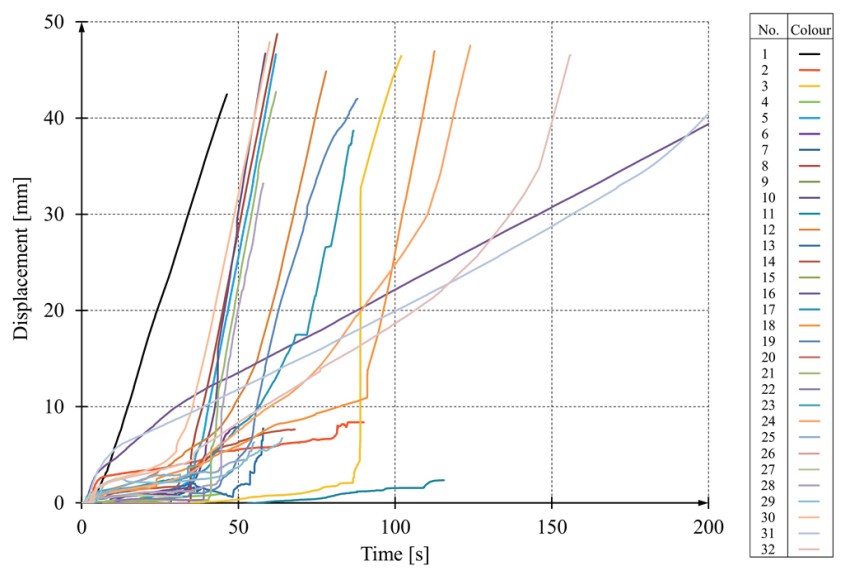

Fig. 20b. Slip on pile free end in masonry specimens

At the initial stage a minor linear change of both values of slip was observed each time. At the next stage there was quite rapid growth of slip increment but it still remained close to linear.

Along with slip increment on the free surface the pile relaxation was observed and the difference between the values of slip on both pile ends decreased. At the final stage the difference between displacements of both materials on the contact surface grew 
rapidly, followed by the total loss of the connection. The piles were dislocated from the specimens and the specimens destroyed.
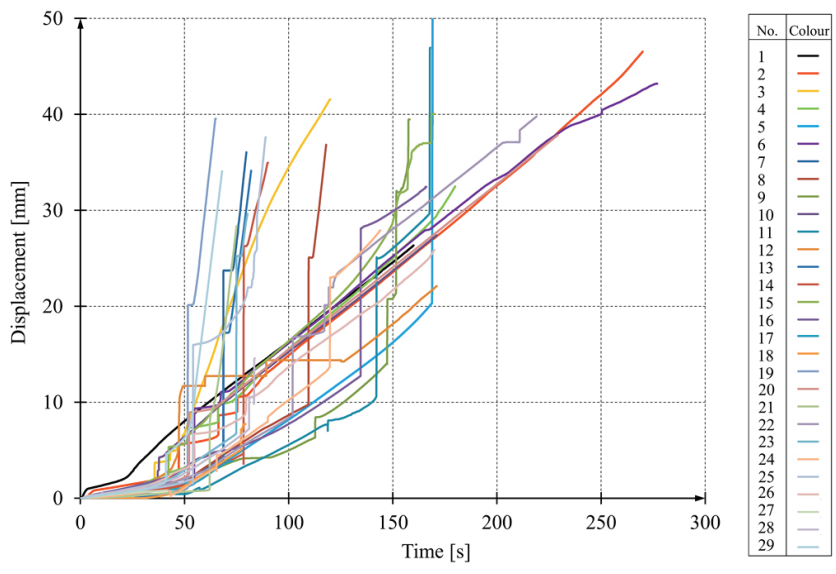

Fig. 21a. Pile slip on load application plane in concrete specimens over time
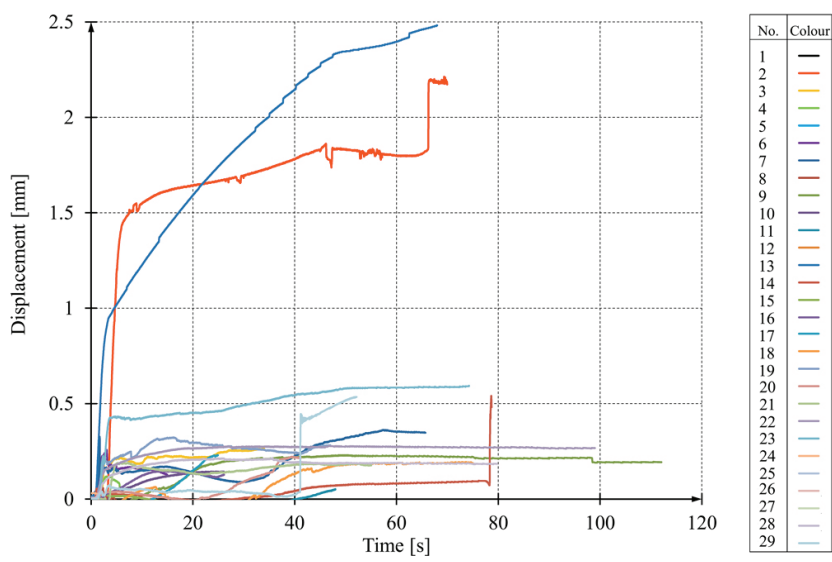

Fig. 21b. Slip in pile free end plane in concrete specimens

In Figs. 22a and 22b, the relationships between the magnitude of loads applied to the pile and the adjacent slip are presented. At the first stage a load increment is followed by slip increment. After reaching the maximum value the magnitude of load decreases and the process becomes unstable. The same curves were obtained for both masonry and concrete specimens.

Let us adopt the value of slip corresponding with the maximum force reached by pile-foundation connection as a limit for allowable design range.

The value of this slip can be adopted as limit $\operatorname{slip} w_{k}^{l}$

It should be assumed that the adopted values of serviceability limit state or technological limitations are less than limit slip, so they are in the range of stable work of the connection.
Such adopted value of limit slip is a random value. Figure 23 illustrates normal distribution of probability density function for specimens modelling masonry and concrete foundations. $w_{k, m}^{l}$ is an mean value and $\sigma$ is standard deviation.
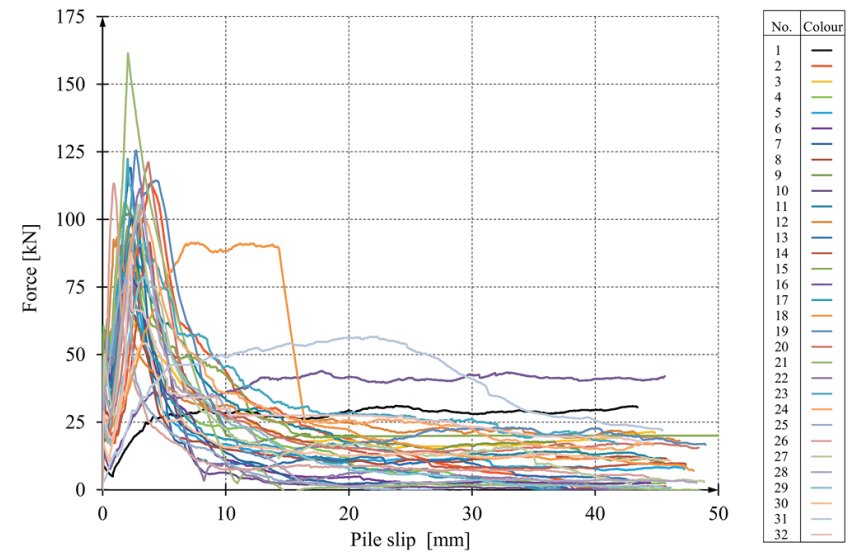

Fig. 22a. Relationships between loads applied to pile and slip on the contact surface for brick specimens
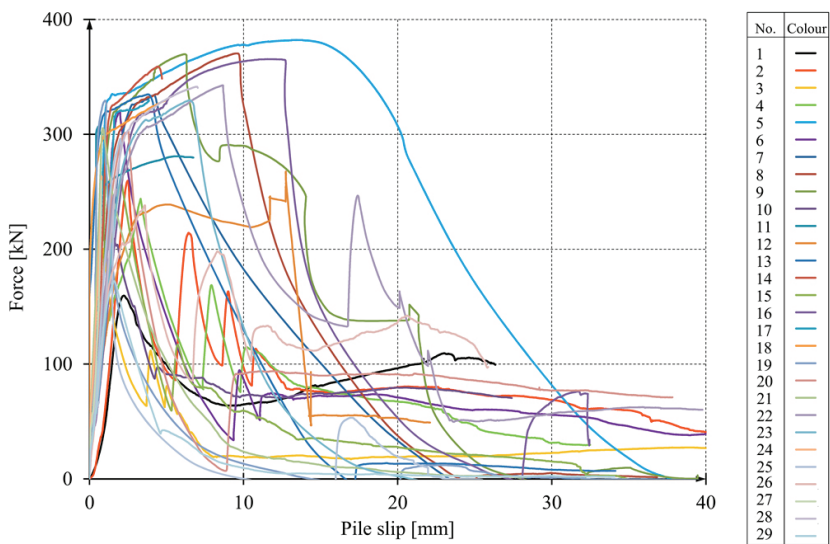

Fig. 22b. Relationships between forces applied to pile and slip

on a contact surface in concrete specimens

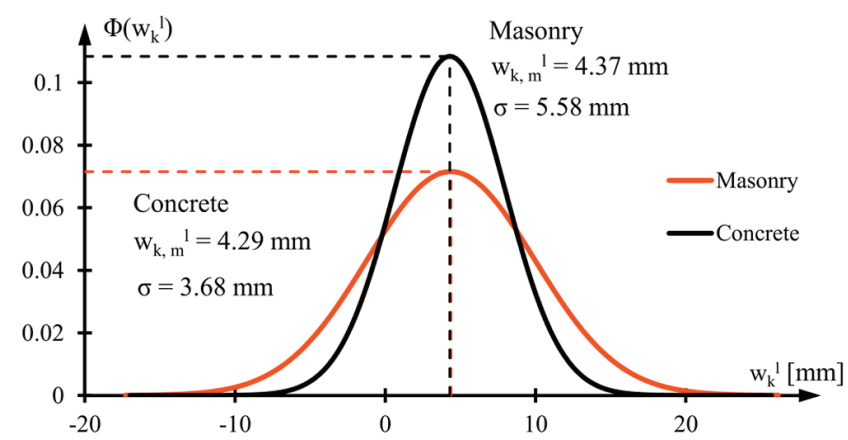

Fig. 23. Probability distribution of limit slip for specimens tested 
What is conspicuous is the convergence of limit slip for both types of specimen. For such different materials of which foundations are built the difference between mean limit values of slip is less than $2 \%$. This fact indicates that it is the properties of the material the pile is made from that decides of the value of the limit slip. The tests presented revealed (Photos 14, 15) that at final stage of load application the free end of the pile undergoes damage. This part of a pile is deformed the least and the pile is pulled out from the foundation in both types of specimens.

The difference between standard deviations is justified by intuition. The masonry foundation built from two different types of materials (brick and mortar) is more non-homogenous and, in consequence, the randomness of obtained results is significantly higher.

\section{PROPOSITION OF DESIGN CONDITION FOR PILE ANCHORAGE IN FOUNDATION}

The results obtained from the tests indicate that in many engineering cases the bearing capacity of the pile anchorage in foundation can significantly affect safe design solutions. It seems reasonable and necessary to introduce additional design conditions. In the article these conditions are proposed as stated conditions (1) and (4). Limit value $F_{k}$ is proposed to be adopted in the following form

$$
F_{k}=R_{G}(5 \%) A
$$

where $R_{G}(5 \%)$ is the guaranteed value of connection strength and $A$ is the surface of the connection.

With no technological restrictions the slip should adopt values in the range of stable work of pilefoundation connection

$$
w_{k}^{l}=w_{k, m}^{l}
$$

where $w_{k, m}^{l}$ is proposed as the mean value of limit slip.

In engineering practice the suggested design conditions are directly translated into the required length of anchorage. This length is strongly dependent on the foundation construction technology.

However, it remains an open question as to the possibility of adopting factors of safety that can de- pend on technological aspects and conditions on construction site.

\section{FINAL REMARKS}

The tests presented in the paper should be treated as a preliminary identification of the mechanical processes on pile-foundation contact surface subjected to loading. Complete verification of such processes requires test to be continued. The experiments were conducted at fixed geometry of specimens and a fixed distance between the pile and the foundation edge. This distance may have a significant influence on the pile-foundation anchorage bearing capacity. During the experiment the length of anchorage was also specified. For design purposes it is important to know how a change of the anchorage length affects its strength. The relationship need not be linear. Another aspect to be verified experimentally is the influence of the pile periphery on the processes that occur in the contact area. The analysis of the effect of geometry on the pile-foundation connection failure does not resolve the problems whose experimental verification seems to be indispensable. These problems include, for instance, the process of fatigue of the connection or its behaviour under long-term loading.

In view of the tests performed it becomes essential to propose a designer friendly calculation model of solving the contact problem with the possibility of including any function of slip on the contact surface. Both foundation and pile are made from brittle materials. Deformation of these materials is followed by the formation and propagation of microcracks. Their initiation is observed even in micro scale, i.e., from $10^{-8} \mathrm{~m}$ to $10^{-6} \mathrm{~m}$. During the propagation process they reach dimensions measured in "micro" and "meso" scale, i.e. from $10^{-6} \mathrm{~m}$ to $10^{-4} \mathrm{~m}$. This stage of propagation of microdefects (damage) because of their huge amount in every volume measured in "macro" scale, i.e., $\left(10^{-4}-10^{-1}\right) \mathrm{m}$ is described by continuum damage mechanics. In the final stage the defects combine to create macrocracks of dimensions registered in "macro" scale. Immediately before the failure the macrocracks reach dimensions corresponding to the failure surface in the element under loading. To fully describe the processes on the pile-foundation contact area the calculation model should include both the principles of continuum damage mechanics and the analysis of the macrocrack. The series of tests presented in the article completely confirm the nature of the process described above. 


\section{REFERENCES}

[1] PN-EN 1997-1:2008, Eurocode 7 Geotechnical Design, PKN, Warszawa, Poland.

[2] PaChla H., Kotwienie pali iniekcyjnych $w$ betonowych fundamentach, Geoinżynieria drogi mosty tunele, 2011, 31(2), 40-43.

[3] PaChla H., Kotwienie niskociśnieniowych pali iniekcyjnych wciskanych $w$ grunt $w$ wykonanych $z$ cegty, Geoinżynieria drogi mosty tunele, 2014, 46(1), 52-54.

[4] Pachla H., Deformacja i nośność zakotwienia niskociśnieniowych pali iniekcyjnych $w$ betonowym fundamencie przy obciązeniu wciskajacym pal $w$ grunt, Geoinżynieria drogi mosty tunele, 2014, 47(2), 28-32.

[5] PaChla H., Zakotwienie wyciaganych z fundamentu niskociśnieniowych pali iniekcyjnych, Geoinżynieria drogi mosty tunele, 2014, 48(3), 48-52.

[6] Hodurek C., Szyprowski A., Projekt konstrukcyjny wykonawczy: Rozbudowa sklepu IKEA w Krakowie, 2009.

[7] GwizDAŁA K., Fundamenty palowe: tom 1, Technologia i obliczenia, Wydawnictwo Naukowe PWN, Warszawa, 2010.

[8] Сног Сн., Сно SAM-DeOK, Field verification study for micropile load capacity, 10th International Workshop on Micropiles, Washington D.C., United States, 2010.

[9] Wilder D., Cadden A., Traylor R., Comprehensive Load Transferring Micropiles Through Concrete Footings: A Full Scale Test Program, ADSC The International Association of Foundation Drilling, Dallas, 2005.

[10] Scarborough J.A., Newman F.B., Compressive Strength Testing of Micropile Grout, ADSC The International Association of Foundation Drilling, Dallas, 2004.

[11] Bruce D.A., Juran I., Drilled and Grouted Micropiles: State-of-Practice Review, ADSC The International Association of Foundation Drilling, Dallas, 1997.

[12] WeInSTEN G.N., Long-Term Behavior of Micropiles Subject to Cyclic Axial Loading, ADSC The International Association of Foundation Drilling, Dallas, 2008.

[13] Armour T.A., Groneck P., KeEley J.N., Micropile Design and Construction Guidelines Implementation Manual, ADSC
The International Association of Foundation Drilling, Dallas, 2000.

[14] Sabatini P.J., Tanyu B., ARmour T.A., Micropile Design and Construction Guidelines Reference Manual, ADSC The International Association of Foundation Drilling, Dallas, 2005.

[15] Bruce D., Richards JR. T. D., Armour T., Micropile Guide Specification, ADSC The International Association of Foundation Drilling, Dallas, 2003.

[16] Rodriguez-Marek A., Muhunthan B., Seismic Behavior of Micropiles, ADSC The International Association of Foundation Drilling, Dallas, 2005.

[17] MASsoudi N., Some Observations on Micropile Inspection and Testing, ADSC The International Association of Foundation Drilling, Dallas, 2005.

[18] Cadden A.W., Bruce D.A., Bean J.J., The Field Inspection and Documentation of Micropile Works, ADSC The International Association of Foundation Drilling, Dallas, 2005.

[19] ShefFField P., Li Xian-XING, RamireZ D., Micropile bearing plates: are they necessary? 7th International Workshop on Micropiles, Schrobenhausen, Germany, May 3-7.

[20] Veludo J., Júlio E.N.B.S., PinTo P.L, Bond strength of micropile (grout) concrete interfaces in RC footings strengthened with micropiles, 9th International Workshop on Micropiles, London, United Kingdom, May 10-13.

[21] Marques D., Veludo J., Santos P., The influence of hole surface treatment and confinement level in the connection capacity between RC footings and strengthening micropiles, International Workshop on Micropiles.

[22] Veludo J., Júlio E.N.B.S., DiAS-DA-Costa D., Compressive strength of micropile-to-grout connections, Construction and Building Materials, 2012, 26, 172-179.

[23] Veludo J., Dias-DA-Costa D., JÚlio E.N.B.S., Pinto P.L., Bond strength of textured micropiles grouted to concrete footings, Engineering Structures, 2012, 35, 288-295.

[24] Gómez J., CAdDen A.W., Traylor R.P., Bruce D.A., Connection capacity between micropiles and existing footings-bond strength to concrete, [in:] D.A. Bruce, A.W. Cadden (eds.), Geo3 GEO Construction Quality Assurance/Quality Control Conference Proceedings, TX: Dallas/Ft. Worth, 2005, 196-216. 